\title{
Objectives and Incentives: Evidence from the Privatization of Great Britain's Power Plants*
}

\author{
Thomas P. Triebs ${ }^{\dagger} \quad$ Michael G. Pollitt ${ }^{\ddagger}$
}

December 17, 2018

\begin{abstract}
Does privatization increase plant productivity because the private owner's objective is different, or because she is better able to control management? And, is privatization sufficient to improve productivity, or is it only effective in combination with competition? We answer these questions using the quasi-experiment of Great Britain's electricity industry privatization. To separate the effect of a change in objectives from a change in incentives we assume, that the former only affect labor but not fuel productivity. And, assuming that effective competition was only introduced after privatization, we are able to separately identify the effects of privatization and competition. We find that privatization increased labor but not fuel productivity: evidence for the importance of objectives. There is no evidence that the introduction of effective competition after privatization increased labor or fuel productivity: evidence that privatization increases productivity by itself.
\end{abstract}

Keywords: privatization, competition, productivity, electricity generation JEL Classification No: L33, L22, L94

\footnotetext{
${ }^{*}$ We would like to thank the participants of the Mannheim Energy Conference 2017, EARIE Maastricht 2017, as well as the research seminars at ETH Zurich, Loughborough University London, and the Nottingham Business School for their comments and feedback. We would also like to thank Catherine Waddams, David Newbery, Paul Kattuman, Luis Orea Sanchez, David Saal, Justin Tumlinson, Oliver Falck, Roger Witcomb, Jaap Bos, Gerald Granderson, Robin Sickles, and two anonymous reviewers for their valuable comments. Last, we would like to thank former research assistants as well several companies for helping with the data collection. The usual disclaimer applies.

${ }^{\dagger}$ Corresponding author: School of Business and Economics, Loughborough University, LE11 3TU, UK, Email: t.triebs@lboro.ac.uk

${ }^{\ddagger}$ Judge Business School and Energy Policy Research Group, University of Cambridge, Trumpington Street, Cambridge CB2 1AG, UK.
} 


\section{Introduction}

Productive efficiency is an important driver of economic welfare (Leibenstein, 1966). Theoretically, both private ownership and competition increase the productive efficiency of firms and plants, but there are alternative explanations for why privatization increases productive efficiency. In this paper we empirically analyze whether privatization increases plant productivity due to changed objectives or changed incentives. Related to these alternative causes is a debate about whether privatization itself increases productivity or whether privatization increases productive efficiency only in combination with competition. We analyze whether the combined effect of privatization and competition is different from the effect of privatization only. Public ownership of firms is still widespread and in some countries, in particular the United Kingdom, there is a debate about reversing privatizations. Knowing why privatization increases productive efficiency, if at all, is important for mitigating any inefficiencies from public ownership, where it has benefits, e.g. lower cost of capital or mitigating externalities. This requires a causal identification of the effects but also of the mechanisms.

To study the effects of privatization and competition on productivity we use the case of Great Britain's (GB) electric industry reforms: restructuring and privatization (R\&P) in 1990/1991 and subsequent competition reforms in the second half of the 1990s. The GB case is of interest, because it was one of the earliest and most pervasive utility industry reforms in the world 1 With the availability of comparable US plants as control group we can identify the effects using standard fixed effects (difference-in-difference) estimation.2 Plant-level productivity is modeled as the intercept, i.e. treatment indicator, in an input demand function derived from a model of constrained cost minimization (Biesebroeck, 2003). Despite the main identification concern being omitted variable bias at the treatment, i.e. country level, the use of micro data has advantages. Micro data allows better comparability by selecting specific plants only. Also, estimation at the plant level increases precision, because we can include relevant control variables for the dependent variable (Angrist and Pischke, 2008, p. 23). We collected unique, plant-level, physical input-output data for a sample GB electricity generation plants for the years 1981 to

\footnotetext{
${ }^{1}$ For an overview of the reform literature see Pollitt (2012)

${ }^{2}$ There is a large literature comparing the cross-sectional performance between public and private firms. For instance, Pollitt (1995) finds no productivity difference. Arocena and Waddams Price (2002) find that the productivity difference depends on the type of regulation. Then there is a large literature making beforeafter comparisons. D'souza and Megginson (1999) find that operating efficiency increased for a sample of 85 privatizations across developed and developing countries, over the years 1990 to 1996 . They find employment reductions only for firms in developed countries. Waddams Price and Weyman-Jones (1996) show that productivity growth increased after the privatization of the British gas industry but that more effective competition would have produced even bigger benefits. Newbery and Pollitt (1997), using a simulated counterfactual showed that the privatization of the UK's electricity industry increased welfare and that technical efficiency gains were larger than allocative efficiency gains.
} 
2004 and matched it to an extended version of Fabrizio et al. (2007)'s data for US, publicly owned plants. The cross-country comparison minimizes the risk that treatment effects spill over to the control group. Generally, utility industries provide good cases to test predictions for the effects of privatization and competition, because the technology (here electricity generation from coal) is easy to characterize using observable inputs and outputs, has inputs and outputs that are homogeneous and measurable in physical units, is globally available, and has not experienced any technological disruptions over our sample period. Last, most plants in the treatment group continue which allows ruling out that any effects are primarily due to selection (Syverson, 2004).

Besides the causal identification of the effects our main contribution is the identification of mechanisms. To test the relative importance of the incentive and the objective mechanisms we use the fact that two important inputs for electricity generation, fuel and labor, are complements in a short-run production function. This allows us to analyze productivity changes for labor and fuel separately. ${ }^{3}$ When we also assume that the fuel input decision (unlike the labor input decision) at the plant level is independent of the owner's objectives, i.e. burning extra fuel does not benefit any political constituency $]_{4}^{4}$ we can use the contrast between labor and fuel productivity changes as evidence for the relative importance of the incentive and objective mechanisms. To separate the effects of privatization and competition we use the fact that in GB effective, as opposed to formal, competition was only introduced several years after privatization.5 We test whether the combined effect of effective competition and privatization was different from the effect of privatization only, assuming that there was no delayed effect of privatization itself.

The theoretical literature provides detailed explanations for the incentive and objective mechanisms. Assuming that both public and private owners' objective is profit maximization, private owners might be better able to solve the principal-agent problem where ownership and control are separate $6^{6}$ Private owners might find it easier than public owners to align their objectives with managers' objectives, because public ownership is very diffuse (Shleifer, 1998) or because

${ }^{3}$ Following Fabrizio et al. (2007) and others we assume that incentives can affect labor and fuel productivity in the short-run. Bushnell and Wolfram (2005) analyze the effect of divestiture on the fuel efficiency of fossil fuel powered plants. They found that divestitures increase fuel efficiency by 2 per cent compared to utility owned plants. They also found that higher powered regulatory incentives had about the same effect as divestitures for utility owned plants.

${ }^{4}$ Consideration for miners certainly influenced the overall fuel mix as well as the ability to import cheap foreign coal. But talking to industry participants that witnessed events it seems unlikely that miners' political power influenced plant-level fuel input decisions.

${ }^{5}$ For the US, Fabrizio et al. (2007) find that full retail liberalization several years after the introduction of competition had additional effects on input productivities.

${ }^{6}$ We assume that ownership and control are separate for both public and private plants. 
public owners are unable to apply hard budget constraints (Schmidt, 1996). Another strand of the theoretical literature assumes that public and private owners have different objectives for the firm. Public, unlike private owners, want to subsidize employment to maximize votes. If the political cost of subsidizing employment through public firms is lower than through private firms, privatization increases labor productivity (Shleifer and Vishny, 1994; Boycko et al., 1996).

There is prior evidence that ownership affects labor productivity more than fuel productivity. Although they do not discuss this result in their paper, Fabrizio et al. (2007) show that in the US, during the late 1980s publicly owned power plants had decreasing labor, but constant fuel productivity, compared to investor-owned plants. Atkinson and Halvorsen (1986), comparing regulated private and public utilities, find a similar result using price inefficiency. Similarly, for nuclear generation plants, Pollitt (1996) shows that whereas fuel productivity does not differ across ownership types, labor productivity is much higher for privately owned plants. Although Chinese reforms of the electricity industry are very gradual and somewhat opaque, the empirical evidence is that labor productivity increased more than fuel productivity (Gao and Van Biesebroeck, 2014, Du et al., 2009).

Closest to our work is Gupta (2005) who empirically separates the incentive and objective effects assuming that partial, i.e. cash flow privatization as opposed to full, i.e. control right privatization can only possibly affect productivity via the incentive mechanism. She assumes that after partial privatization, minority shareholders can influence management incentives but not the firm's objective. Her finding that partial privatizations in India in the 1990s increased firm-level labor productivity, is evidence that the incentive mechanism matters. She also finds some suggestive evidence that full privatization increased labor productivity further, i.e. the objectives mechanisms is also important, but due to data limitations is not able to test the effect of full privatization formally. Effectively, this data limitation does not allow her to find that only objectives matter. But just like hers our natural experiment has limits, too. For instance, if we found that privatization increased both labor and fuel productivity we could not tell whether this was due to the incentive effect or some combination of both effects.

Incentives based arguments for why privatization increases productivity are often similar to arguments for why competition increases productivity, which gives rise to a debate about whether privatization itself increases productivity (as in Schmidt, 1996) or whether the effect of privatization is conditional on environmental factors, in particular competition. In principalagent settings the threat of bankruptcy (Schmidt, 1997), better information (Hart, 1983), or increased sensitivity of profits to managerial effort (Willig, 1987) can explain why competition increases productivity. Nickell (1996) summarizes these theoretical arguments. Empirically, 
there is evidence that competition increases the productive efficiency of firms and plants Nickell, 1996, Galdón-Sánchez and Schmitz, 2002, Fabrizio et al., 2007). There is also evidence that the effect of competition is more important than the effect of ownership (Caves and Christensen, 1980, Bartel and Harrison, 2005).

We find that whereas labor productivity increased substantially after privatization fuel productivity did not. This is evidence, that privatization improves productivity via changes in objectives rather than incentives, and is consistent with some of the cross-sectional evidence in the literature. The introduction of effective competition after privatization did not increase labor or fuel productivity (further). Given the strong prior evidence that competition does increase productivity, we conclude that in our case competition never became effective during the 1990s. In any case we find evidence that privatization is sufficient to increase productivity, which is of course consistent with the finding that privatization increased productivity due to changed objectives. When considering public ownership it is important to guarantee that the firm objective is efficient production.

The outline is as follows. Section 2 provides some background on GB electricity R\&P and the identification strategy. Section 3 describes our empirical approach. Section 4 describes the data. Section 5 gives the results and section 6 concludes.

\section{Background and Identification}

Before R\&P in 1991, the generation and transmission of electricity in England \& Wales was the responsibility of the Central Electricity Generation Board (CEGB), a horizontally and vertically integrated state-owned monopoly. Distribution in England \& Wales was the responsibility of 12 regional monopolies, the Area Boards. In Scotland and Northern Ireland vertically integrated, regional monopolies were responsible for generation, transmission, and distribution.7 Even though the Scottish reform process was slightly different, we include Scottish plants in this study. Northern Irish plants are excluded, because Northern Ireland was not interconnected with Great Britain during our sample period.

A first attempt to liberalize the market was undertaken in 1983 when the Energy Act required the Area Boards to buy energy from independent (non-CEGB) generators at avoided cost. As the Act did not protect entrants from the incumbent's anti-competitive behavior the reform was ineffective (Vickers et al., 1991). Eventually, the electricity industry in England and Wales was restructured between 1988 and 1990, and privatized in 1991. In Scotland the

\footnotetext{
${ }^{7}$ Whereas Scotland had two companies, Northern Ireland had a single electricity company.
} 
industry was also privatized in 1991 but was not restructured immediately $\sqrt[8]{8}$ Restructuring in England and Wales comprised the vertical unbundling of generation and transmission as well as the horizontal separation of generation .96 Generation assets were separated into four companies: all fossil-fuel plants were divided between PowerGen and National Power (our sample), the new transmission company National Grid obtained pumped storage plants, and Nuclear Electric the nuclear plants. Sixty percent of the shares in PowerGen and National Power were sold to the public in 1991. The remaining shares were sold in February 1995. There is no evidence that the government retained control after 1991, but continued government ownership might have created a conflict of interest in relation to competition. Part of Nuclear Electric was only privatized in 1996 (as British Energy) and is not included in this study. The Area Boards and the transmission company became private, regulated monopolies. We identify the privatization effect by comparing the productivity change for GB generation plants before and after 1991 to the productivity change of publicly owned US plants. To the extent that there are pure separation effects (vertical or horizontal) our privatization effect captures these, too. Our identification assumes that privatization was exogenous, which it might not have been. However, it does not appear that privatization was endogenous to short-run, plant-level productivity performance. It is more likely that it was endogenous to long-run investment performance and political considerations like private share ownership. 10

Even though a deregulated wholesale market was established at R\&P, competition among electricity generators was not effective, because National Power and PowerGen formed a duopoly for fossil-fuel generation (Sweeting, 2007). Government gave the newly created firms market power to maximize the proceeds from privatization (Henney, 2010, p. 37). Moreover, the rules of the newly established wholesale market, referred to as the Pool, facilitated the exercise of market power (Green, 2006). Also, at R\&P only sales to industrial customers (above $10 \mathrm{MW}$ ) were deregulated, partly to burden retail customers with the high cost of British coal, which plants had to buy. Prices for other customers were deregulated in stages until retail was fully deregulated in 1999.

A few years after R\&P, high electricity prices and profits shifted political attention from ownership to competition. As a first measure the regulator capped wholesale prices between 1994 to 1996 . Then, in 1996 and again in 1999 incumbents divested plants to competitors.

\footnotetext{
${ }^{8}$ See Pollitt (1997) and Pollitt (1999) for a discussion of the Northern Irish and Scottish cases, respectively.

${ }^{9}$ In the US restructuring often refers to the introduction of competition, i.e. market liberalization.

${ }^{10}$ Margaret Thatcher herself summarized the objective of her reform by saying: "Economics are the method; the object is to change the heart and soul." (Sunday Times, 3 May 1981)
} 
There is evidence that only the second round changed firm behavior. In the first round plants were leased to a single competitor and lease contracts were such that the new owner had no incentive to compete (Henney, 2010, p. 37). Sweeting (2007) provides evidence that firms (tacitly) colluded throughout the second half of the 1990s. In 1999 the incumbents sold plants to various (mostly foreign) investors in return for regulatory permission to vertically integrate with the supply function. For example, Edison Mission bought two plants in 1999 and increased output by $30 \%$ (Newbery, 2004, p. 18), which is unlikely to be the result of efficiency increases alone. Probably, the entry of foreign owners in the late 1990s ended tacit collusion between the generators. Overall, market concentration for generation decreased considerably throughout the 1990s. For coal fired plants, the Herfindahl Hirschman index, a measure of market concentration, had dropped by 1999 to a fifth of its value in 1991. Just like for most other quasi-experiments of this type the introduction of competition was not fully exogenous. However, we test alternative dates for the onset of effective competition. Given this reform history the obvious choice for the privatization date is 1991, but the choice for the onset of effective competition is less obvious. As it seems that the introduction of full retail competition and plant divestitures in 1999 had a bigger impact on competition than the earlier measures, we choose 1999 as our preferred date for the introduction of effective competition. However, we also test 1996, the year when wholesale price regulation ended and the first divestiture round occurred, as an alternative date. Last, we acknowledge that like most studies in this area we have a single treatment case. Thus, a general threat to identification is that we cannot control for fixed effects at the treatment level.

\section{Empirical Model}

Estimating productivity (change) requires a model of the technology that converts inputs into outputs. We apply a model developed by Biesebroeck (2003) and previously applied by Fabrizio et al. (2007) and Gao and Van Biesebroeck (2014), because it allows us to separately estimate productivity shifts for fuel and labor. The model uses the fact that observed plant-level electricity output is the minimum of what the manager planned to produce and what she is required to produce by the system operator. The difference between planned and actual output captures the temporal sequence of input decisions and the resulting constraints on short-run input substitution, which allows us to treat fuel and labor as complements.

In this model actual production is the minimum of planned (or "probable") output $Q^{P}$, which is a function of capital and labor, and fuel input $g(\cdot)$. Actual output $Q^{A}$ for plant $i$ in year $t$ takes the following Leontief form: 


$$
Q_{i t}^{A}=\min \left[g\left(E_{i t}, \Gamma^{E}, \epsilon_{i t}^{E}\right), Q_{i t}^{P}\left(K_{i}, L_{i t}, \Gamma^{P}, \epsilon_{i t}^{P}\right) \exp \left(\epsilon_{i t}^{A}\right)\right]
$$

$\Gamma$ denotes coefficient vectors and $\epsilon$ represents error terms. Actual output (observed by the researcher) could be more or less than planned output, depending on differences between actual and expected demand as well as unexpected changes in plant availability. Thus, $Q^{A}=$ $Q^{P} \exp \left(\epsilon_{i t}^{A}\right)$, i.e. actual output equals probable output multiplied by a shock that is observed by the plant manager at the time of actual production. $\epsilon_{i t}^{P}$ is observed by the plant manager but at the time of planning. Planned output is a function of capital $K$ and labor $L$, but capital is considered fixed to reflect the short-run nature of the production function. Planned output is not a function of fuel, because the amount of fuel is determined by actual output. Intuitively, whereas the amounts of non-fuel inputs are chosen before production takes place fuel input depends on actual production. For our analysis of the mechanisms the crucial property of this production function is that it does not allow labor to substitute for fuel in the short-run. Also, neither in the medium nor the short-run can the plant manager substitute labor for capital. Next, we derive the demands for labor and fuel for this model.

We derive labor demand assuming cost minimization behavior constrained by a Cobb-Douglas production function for probable output $Q_{i t}^{P}=Q_{0}\left(K_{i}\right) L_{i t}^{\rho} \exp \left(\epsilon_{i t}^{P}\right)$. Again, capital is fixed. Given a short-run objective function that minimizes labor cost, $\min W_{i t} \times L_{i t}$, we can derive the following labor demand equation:

$$
\ln L_{i t}=A_{0}+\ln Q_{i t}^{A}-\ln W_{i t}-\epsilon_{i t}^{L},
$$

where labor input $L$ is a function of actual output $Q^{A}$ and the wage $W$. Note that labor input is a function of $Q^{A}$, because $Q^{P}$ is unobserved and we substitute using $Q^{A}=Q^{P} \exp \left(\epsilon_{i t}^{A}\right)$. The constant $A_{0}=\ln (\lambda \rho)$, has two components: the Lagrangian multiplier or shadow value of changes in the output constraint $\lambda$ and the labor parameter $\rho$ or marginal productivity from the production function. In the empirical specification a number of proxies control for $\lambda$ and the change in $\rho$ is captured by the treatment indicator.

The derivation of the fuel demand follows a different strategy as the fuel input is not part of the optimization problem used to derive the demand for labor. We only need to assume that $g(\cdot)$ is monotonically increasing in fuel $E$ and inversion produces the following fuel demand 
equation:

$$
\ln E_{i t}=\gamma_{Q} \ln Q_{i t}^{A}+\epsilon_{i t}^{E},
$$

where $\gamma$ is the output coefficient. Unlike for labor the fuel demand function does not depend on input price. As plants are scheduled by a central planner before actual production, actual production does not depend on the price of fuel, only the schedule (or merit order) does.

We need to expand these theoretical demand equations by a set of indicator variables to identify the difference in the productivity change between treated and non-treated plants from before treatment to after treatment. We use one indicator for each of the two treatments: $\delta^{P}$ indicates if the plant is privatized, i.e. the indicator takes the value one if the plant is in GB after 1991 and before 2000 (alternatively 1997), $\delta^{C}$ indicates if the plant is privatized and exposed to effective competition, i.e. the indicator takes the value one if the plant is in GB after 1999 (or alternatively 1996). To the extent that the effect of privatization is time-invariant, $\delta^{C}$ captures the effect of privatization and competition, and the difference between $\delta^{C}$ and $\delta^{P}$ captures the effect of competition only. If the effect of privatization was not time-invariant but for instance increased over time, $\delta^{C}$ would overestimate the true effect of competition and $\delta^{P}$ would underestimate the true effect of privatization. To investigate whether the treatment effects are likely to be time-invariant and whether there are anticipatory effects we also estimate a version of the model where we replace $\delta^{P}$ and $\delta^{C}$ by a set of indicators for each year from 1985 to 2004.11 To minimize the bias and to improve the precision of the estimated treatment effects we add a number of control variables. First, we add plant fixed effects $\alpha_{i}$ to control for any unobserved cross-sectional differences across plants like climate, technology, or time-invariant differences in regulatory regimes. Second, we add year fixed effects $\alpha_{t}$ to control for technological progress for all plants. There might be other time-variant, region-specific effects like regulatory change, but region-year fixed effects would be collinear with the treatment indicators ${ }^{12}$ However, we add region-specific trends $\alpha_{r} t$ which go some way in capturing time-varying regional differences. Region is defined as a US state or GB. We take state-level trends, because in the US regulatory decisions equivalent to the GB policy changes considered here are mostly taken at the state level. Third, we add observed controls, to have additional proxies for the unobserved output constraint $\lambda$, to improve the precision of the treatment effect estimates ${ }^{13}$ and to make it more

\footnotetext{
${ }^{11}$ Note we can only investigate anticipation for privatization, because for the competition treatment we cannot separate the effect of privatization and anticipation of the competition effect.

${ }^{12}$ To fully separate the treatment effects from contemporaneous shocks we would require multiple treatments with differential timing, which is simply not available for our natural experiment.

${ }^{13}$ Even if uncorrelated with the treatment, controls that correlate with the dependent variable increase the
} 
likely that the common trends assumption holds. We include a variable for plant age (AGE) ${ }^{14}$ We control for capital using net capacity (CAP) and the presence of SO2 abatement technology (FGD). We also control for output (NET GWH) as well as the load factor (LF), as the scale at which a plant operates affects productivity. After R\&P plants might have been called upon in a different order (their position in the merit order changed), which would affect performance (Knittel, 2002). The load factor might also control for different operating patterns. Bushnell and Wolfram (2005, p. 2) state that for fuel "irregular operating patterns motivated by attempts to exercise market power and the disruption of an ownership change could diminish operating efficiency at least in the short-run". With these additional variables the empirical labor demand equation is

$$
\begin{aligned}
\ln L_{i g t} & =\alpha_{i}+\alpha_{t}+\alpha_{r} t+\delta_{i t}^{P}+\delta_{i t}^{C}+\beta_{1}^{N} \ln N E T G W H_{i g t}+\beta_{2} \ln W_{i t} \\
& +\beta_{3} F G D_{i t}+\beta_{4} A G E_{i t}+\beta_{5} L F_{i t}+\beta_{6} \ln C A P_{i t}+e_{i t},
\end{aligned}
$$

where the error term $e$ combines the deviation from planned output $\epsilon^{A}$ and an input-specific error $\epsilon^{L}$. To make our standard errors robust to unobserved, persistent productivity shocks we follow Bertrand et al. (2004) and cluster errors at the treatment level, i.e. the clusters are US states or GB. The empirical form for fuel (not shown) is identical but omits the input price variable. As our data has gaps, in particular for labor, and we want to maximize the number of observations we estimate the two input demands for different samples. We have no reason to believe that plants did not report inputs strategically and assume that gaps are random. Nevertheless, we also report results for sub-samples where both inputs are non-missing.

Generally, identification requires that i) all control variables are exogenous and ii) that given the controls the treatments are as good as random. Possible endogeneity for the control variables comes in two forms. First, the treatment could directly influence one of the control variables, which we rule out. Second a control variable could be correlated with the error term 15 . Although unlikely for electricity generation due to fixed contracts and the fact that output is set by a system operator, we test the robustness of our results to instrumenting for output. Output is more likely to be endogenous for fuel than for labor productivity, because plant managers are

precision of the coefficient estimates for the treatment effect (Angrist and Pischke, 2008, p. 23).

\footnotetext{
${ }^{14}$ Joskow and Schmalensee (1987) found that plant performance "deteriorates significantly" with age. However, Hiebert (2002) showed that length of service might actually increase performance as plant management learns to better operate the plant. Pollitt (1995, p. 132) found no significant age effect for a sample of base load plants.

${ }^{15}$ Endogeneity is only a concern if $E[e \mid X]$ is non-linear in $X$ Frölich, 2008, p. 218)
} 
less likely to be able to adjust the latter in response to productivity shocks in the short run. We instrument for output using its first lag, which has the advantage of being firm specific. The first lag is a valid instrument if it correlates with current output and if it does not correlate with the error term (exclusion restriction). When using a lag as instrument the exclusion restriction requires the assumption of no serial correlation. Following Fabrizio et al. (2007), we also considered aggregate sales and its interaction with region indicators ${ }^{16}$ as an instruments, but the first stage is not significant. Tables 4 and 5 in appendix $\mathrm{A}$ compare the two instrument sets and show that for our data lagged output is the better instrument. Estimating similar input demand functions for electricity generation Fabrizio et al. (2007) and Gao and Van Biesebroeck (2014) find that the qualitative results are robust to the use of different instruments for output.

\section{Data and Summary Statistics}

\subsection{Great Britain}

We collected coal fired generation plant-level data for physical inputs and outputs from various sources. Restricting our sample to coal fired plants maximizes comparability over time and across the two countries. First, we collected all data that is publicly available, e.g. from industry statistical yearbooks, firm reports, and government sources. Second, we contacted firms directly and received additional data, but gaps remain. We contacted the owners of the majority of plants but some did not respond. For fuel type and generation capacity, which are unlikely to change from year to year we fill gaps (once not recursively) with adjacent values. Also, we replace missing values for the amount of electricity supplied by the amount generated. For GB's largest coal fired plant we only observe the average labor input before privatization and we assume that for the years before privatization its labor input was constant. Also, we use physical/engineering relationships to replace missing values for some variables using other observed variables. Before privatization fuel input is not observed directly, but the CEGB yearbooks report plant-specific thermal efficiencies, which we use to derive fuel input.17 Also, as plant-level $\mathrm{CO} 2$ emissions were calculated from fuel samples, we replace missing fuel input values with values derived from observed $\mathrm{CO} 2$ emissions. For the estimation of labor, but not fuel productivity, we derive missing plant-level output from capacity and fuel-specific efficiency factors. This is reasonable as labor input does not vary that much with output at the plant

\footnotetext{
${ }^{16}$ We add the interactions, because for GB we only observe national sales. The regions are US states or UK regions.

${ }^{17}$ We have no data for fuel input for the years 1988 to 1990 as the CEGB published no yearbooks during the restructuring phase before privatization.
} 
Table 1: Variables and Measurement

\begin{tabular}{|c|c|}
\hline Variable & Definition \\
\hline Fuel & Mtce/year \\
\hline Labour & number of employees/year \\
\hline Output & net GWh/year \\
\hline Capacity & net MW \\
\hline FGD & 1 if FGD fitted; 0 otherwise \\
\hline Age & $\begin{array}{l}\text { number of years since first unit com- } \\
\text { missioned }\end{array}$ \\
\hline Load factor & Proportion \\
\hline Wage & $\begin{array}{l}\text { regional, gross, weekly, pounds at } \\
\text { market exchanges rates }\end{array}$ \\
\hline POSTX & $\begin{array}{l}\text { structural break indicator: } 1 \text { if yeal } \\
>X \text { and country }==\mathrm{GB} ; 0 \text { otherwise }\end{array}$ \\
\hline
\end{tabular}

level. For details see Appendix B. Table 8 in Appendix B compares means for observed and derived values for fuel input and output. It shows that the majority of observations is derived and that we are more likely to derive these values for lower output plants. Effectively, we estimate labor and fuel productivities using different samples. The final sample, after listwise deletion by input, is an unbalanced panel with gaps for the years 1981 to 2004 . For GB and the US we have a total of 1923 plant-year observations for the fuel demand equation and 1718 for the labor demand equation. Table 2 below shows that GB's observation percentages are 25 and 15 for fuel and labor, respectively. Even after replacing some missing values with proxies for GB, many variables still have fewer observations than the 728 plant-year observations identified (see the capacity variable, which is publicly available for all plants). All variables and their measurements are listed in Table 1. We test the robustness of our results to the use of nonmissing values only and to the use of sub-samples where both inputs are observed.

Some variables are adjusted. Whereas some firms report for financial years others report for calendar years. We correct for this by constructing calendar year data from the weighted financial year data (weights are the number of months). We drop observations just after a plant is installed or just before it is shut down, because in these years plants do not operate regularly. We measure the presence of FGD by plant-level dummies. Plants typically consist of several units and the fitting of abatement technology typically occurs over several years, unit by unit. The FGD dummy takes the value 1 if the first unit is fitted.

Wage data is not available at the plant level but at the regional level. The regions are equivalent to Eurostat's first level Nomenclature of Territorial Units for Statistics (NUTS) regions. We take gross, weekly, regional wages from the New Earnings Survey for the years up 
to 1996 and from the Annual Survey of Hours and Earnings for later years. Both survey are published by the UK Office for National Statistics ${ }^{18}$

\subsection{United States}

Our control group is cooperatively and publicly (municipal or federal) owned US plants. The data is from Fabrizio et al. (2007), which is available as an online appendix to their paper. We extend their data to 2004 using commercially available data from Platts. We use both restructuring and non-restructuring states as according to Fabrizio et al. (2007, p. 1259) US restructuring did not change the competitive environment for public utilities, except in Arizona and Arkansas, which we exclude. The wage data is from the Bureau of Labor Statistics' Quarterly Census of Employment and Wages series. For the wage data we have to deal with the change from the SIC to the NAICS industry classification system. The original series is for SIC 4911 (Electric Services). We extend it using NAICS 221112 (Fossil Fuel Electric Power Generation).

Table 2 contrasts comparative statistics for US and GB plants. It gives the group and variable specific means, standard deviations, and number of observations. The third column also gives test statistics for the Null of equal means. We see that GB plants are larger, employ more workers, but have lower load factors. Wages are about double in the US (at market exchange rates). Equality of means is rejected for all variables, but our identification only requires that the productivity trends, in the absence of the treatment, are identical (we test this assumption below).

\footnotetext{
${ }^{18}$ The two surveys are easily combined except for a slight change in regional definitions. Whereas the NES uses English "standard regions" the ASHE uses "regions of England". Except for the North East, South East, and East the definitions are identical.
} 
Table 2: Summary Statistics by Treatment Category

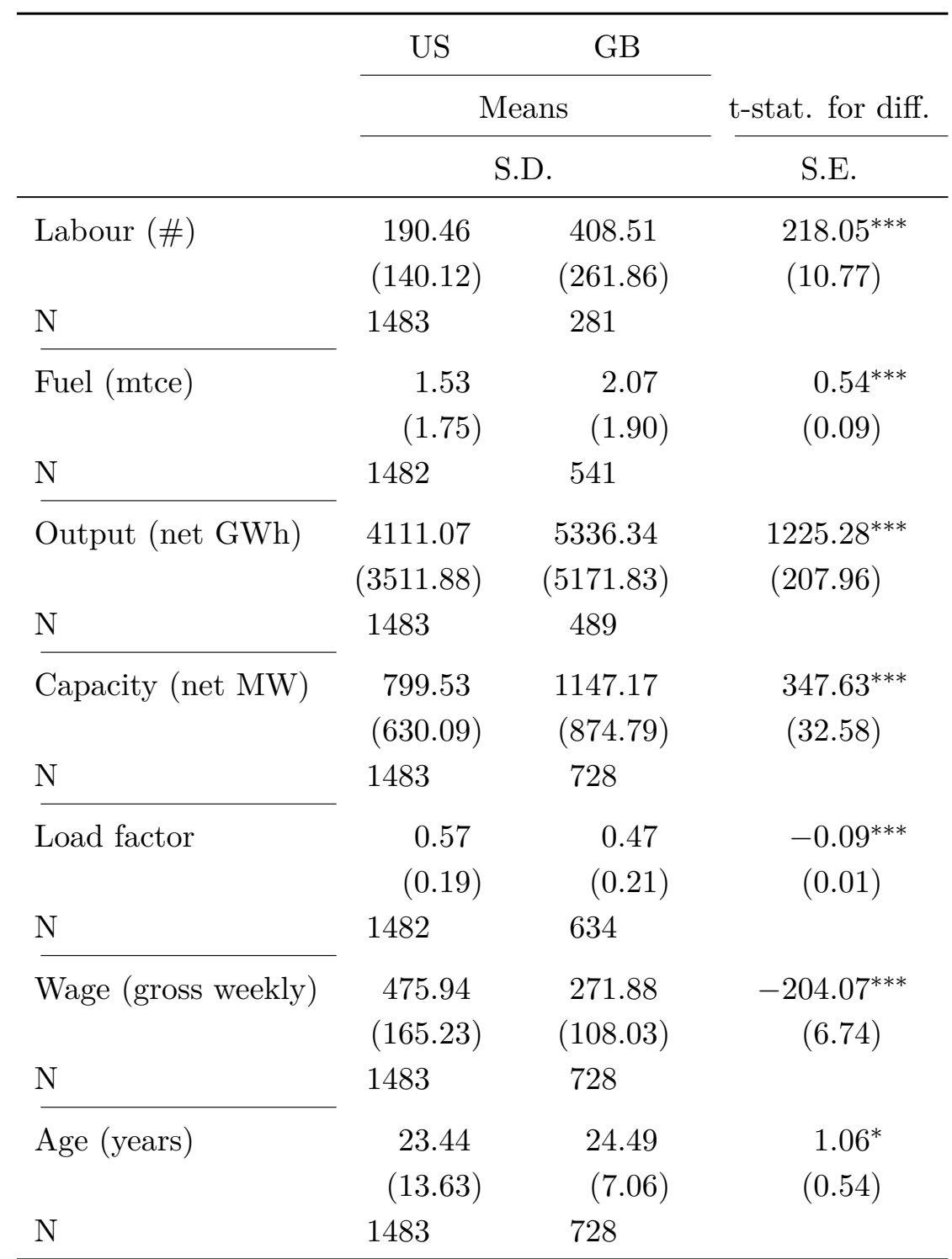

Notes: This table gives the means, standard deviations, and number of observations for each variables for the US (control group) and GB (treatment group). In the third column it also gives the t-statistic and standard error for the Null of equal means. ${ }^{*} \mathrm{p}<0.05,{ }^{* *} \mathrm{p}<0.01,{ }^{* * *} \mathrm{p}<0.001$ 


\section{Results}

Our identification assumes common trends, no anticipatory effects, and constant post-treatment effects. Before looking at our main results we use a slight modification of Equation (4) to test these assumptions. First, the regime-specific treatment indicators are replaced by a set of yearspecific treatment indicators, for a window from 1985 until the end of our sample. Second, we drop the region-specific trends as they are multicollinear with the yearly treatment indicators. Instead of printing a regression table, Figure 1 plots the estimated OLS coefficients (in logpoints) together with their 95 percent confidence intervals. A negative (positive) sign indicates a productivity increase (decrease) in GB relative to the US in a given year. The two vertical lines indicate the treatment dates. Our difference-in-difference identification strategy assumes that had there been no treatment, both the treatment and control groups would have followed a common trend. As the true counterfactual, GB's input productivities absent privatization, are unobserved we cannot test the assumption. But a comparison of the pre-treatment trends for the two groups provides some evidence. For labor and fuel most pre-treatment estimates are statistically insignificant indicating that the pre-trends are similar and therefore that the common-trends assumption is reasonable 1920 At privatization in 1991, GB's labor productivity increased strongly. Even though the initial effect was large the effects grew until 1995, after which they were stable until the end of our sample. As the effects were stable after 1995 it is unlikely that we confuse late effects of privatization with the effect of competition. It seems that the introduction of effective competition in 1999 (or in 1996) had no additional effect on labor productivity.

The bottom panel shows that after privatization, if anything, fuel productivity in GB actually decreased. It then increased in the second half of the 1990s but decreased again after 2000. As there are only two years (1999 and 2000) with statistically significant fuel productivity increases, it is debatable whether competition had a positive effect in the second half of the 1990s.

As we infer missing values from other observed variables for several variables we undertake two robustness tests. First, we estimate each input equation for the sub-samples of observations where the other input is non-missing, too. Second, we restrict the samples to non-missing values only. Figures 2 and 3 in appendix $\mathrm{A}$ give the estimation results. In Figure 3 , as we do not observe actual fuel input before privatization all the pre-treatment effects are missing, which also prevents us from performing the same robustness test for the regressions in Table 3

\footnotetext{
${ }^{19}$ These findings also corroborate the common trends assumption made by Newbery and Pollitt (1997).

${ }^{20}$ There are no estimates for the years 1988 to 1991, because of a gap in the GB data.
} 
below. We see that the results for labor productivity are robust. For fuel the qualitative results are similar, but the magnitudes are less robust. Overall, the two alternative samples provide stronger evidence for a decrease in fuel productivity after privatization and less evidence for an increase due to competition during the 1990s.

A potential drawback of this year-specific treatment effects model is that it might also capture year-specific shocks unrelated to the relevant policy changes. Certainly, the short-run variability of fuel productivity suggests that the indicators might capture shocks other than privatization and competition in GB, too. 


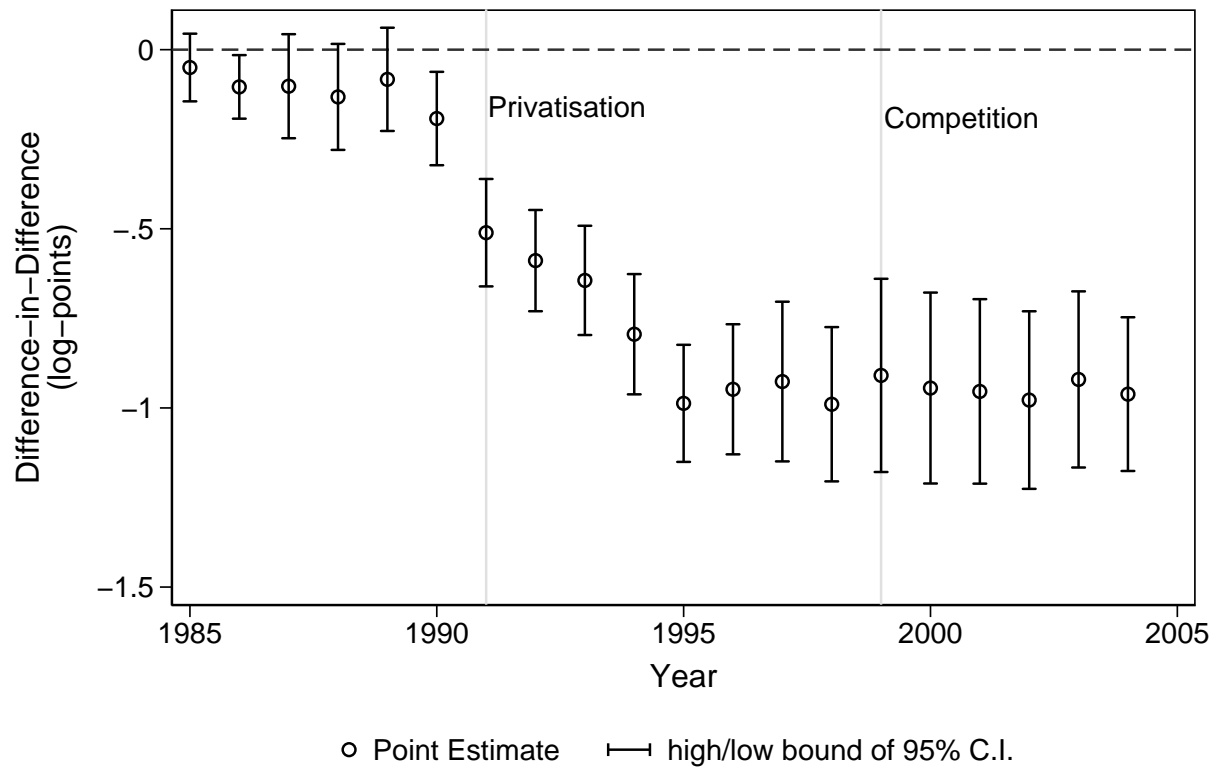

(a) Labor

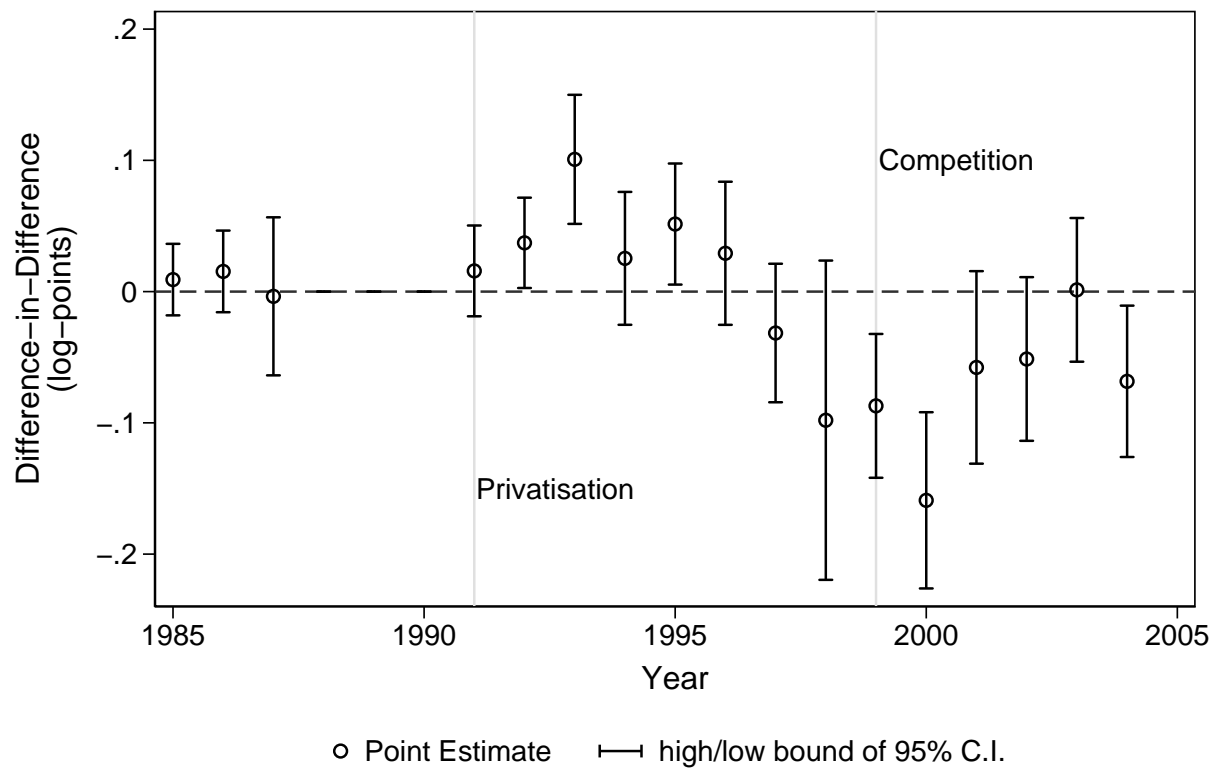

(b) Fuel

Figure 1: Year-specific treatment effects

Notes: The graphs plot the coefficient estimates, in log-points, for the year-specific input productivity differences (treatment effects) between GB and the US, the control group. The differences are estimated as part of input demand equations at the plant level. The estimator is OLS with panel fixed effects and standard errors clustered at the treatment level. The upper panel is for labor productivity and the lower panel is for fuel productivity. The vertical bars give the $95 \%$ confidence intervals. A positive (negative) estimate represents a decrease (increase) in productivity. The two vertical lines indicate the dates for privatization and the introduction of competition in Great Britain. The missing estimates for fuel are due to gaps in the GB data.

Next, we give the results for our main model, Equation (4). Compared to the previous model 
it effectively averages the year-specific effects within the two treatment regimes: privatization from 1991 to 1999 (or 1996) and privatization and competition from 1999 (or 1996) until the end of our sample. Table 3 gives the regression results. Whereas the first three columns give results for labor, the last three columns give the results for fuel. For each input, the first column is for the OLS estimator and the last two columns are for the IV estimator. The IV results in columns (2) and (5) are for the unbalanced sample and the results in columns (3) and (6) are for the "balanced" sample, meaning that a GB plant is observed at least once before 1985 and once after 2001. Thus, even though the sample still has gaps it assures that we identify the effects only for plants that experienced both privatization and the introduction of effective competition and not for instance, plants that exited shortly after privatization.

The coefficient estimates for the control variables are as expected. Whereas the year-on-year variation in labor input is driven by a mix of output and capacity, the fuel input variation is mostly driven by output. For both fuel and labor, the OLS output coefficients are biased downwards, implying a negative correlation between unobserved productivity shocks and input. For instance, during an output reducing plant break down, more fuel and labor might be required. Also, consistent with the Cobb-Douglas form, for most IV output coefficient estimates we cannot reject the Null of unity. As plants age labor productivity decreases, but fuel productivity increases. The presence of FGD abatement technology significantly decreases fuel productivity. 
Table 3: Treatment effects for privatization and competition

\begin{tabular}{|c|c|c|c|c|c|c|}
\hline \multirow[b]{3}{*}{ Balanced sample } & $(1)$ & $\ln$ (Labor) & (3) & $(4)$ & $\ln ($ Fuel $)$ & (6) \\
\hline & \multirow{2}{*}{$\begin{array}{c}\text { OLS } \\
\mathrm{N} \\
\end{array}$} & \multicolumn{2}{|c|}{ IV } & \multirow{2}{*}{$\begin{array}{c}\text { OLS } \\
\mathrm{N}\end{array}$} & \multicolumn{2}{|c|}{ IV } \\
\hline & & $\mathrm{N}$ & Y & & $\mathrm{N}$ & $\mathrm{Y}$ \\
\hline \multirow[t]{2}{*}{$\ln (\mathrm{NET}$ GWH) } & 0.049 & 0.293 & 0.400 & $0.921^{* * *}$ & $1.000^{* * *}$ & $1.088^{* * *}$ \\
\hline & {$[0.39]$} & {$[0.06]$} & {$[0.37]$} & {$[0.00]$} & {$[0.00]$} & {$[0.00]$} \\
\hline \multirow[t]{2}{*}{$\ln (\mathrm{CAP})$} & $0.543^{* *}$ & 0.299 & 0.191 & -0.048 & -0.126 & -0.135 \\
\hline & {$[0.01]$} & {$[0.15]$} & {$[0.69]$} & {$[0.57]$} & {$[0.16]$} & {$[0.51]$} \\
\hline \multirow[t]{2}{*}{$\mathrm{LF}$} & $0.191^{*}$ & -0.395 & -0.619 & -0.040 & -0.217 & -0.369 \\
\hline & {$[0.04]$} & {$[0.23]$} & {$[0.52]$} & {$[0.54]$} & {$[0.21]$} & {$[0.42]$} \\
\hline \multirow[t]{2}{*}{ AGE } & 0.020 & 0.028 & 0.029 & $-0.017^{*}$ & $-0.027^{* * *}$ & $-0.027^{* * *}$ \\
\hline & {$[0.12]$} & {$[0.10]$} & {$[0.07]$} & {$[0.02]$} & {$[0.00]$} & {$[0.00]$} \\
\hline \multirow[t]{2}{*}{$\ln ($ WAGE) } & -0.072 & -0.041 & -0.034 & & & \\
\hline & {$[0.15]$} & {$[0.35]$} & {$[0.49]$} & & & \\
\hline \multirow[t]{2}{*}{ FGD } & 0.042 & 0.009 & 0.006 & $0.043^{* *}$ & $0.043^{* *}$ & $0.036^{*}$ \\
\hline & {$[0.25]$} & {$[0.81]$} & {$[0.89]$} & {$[0.01]$} & {$[0.00]$} & {$[0.02]$} \\
\hline \multirow[t]{2}{*}{ POST1991 } & $-0.373^{* * *}$ & $-0.326^{* * *}$ & $-0.305^{* * *}$ & $0.088^{* * *}$ & 0.062 & $0.094^{* *}$ \\
\hline & {$[0.00]$} & {$[0.00]$} & {$[0.00]$} & {$[0.00]$} & {$[0.16]$} & {$[0.00]$} \\
\hline \multirow[t]{2}{*}{ POST1999 } & $-0.238^{* *}$ & $-0.208^{* *}$ & $-0.184^{* *}$ & $0.128^{* *}$ & 0.064 & $0.135^{*}$ \\
\hline & {$[0.00]$} & {$[0.00]$} & {$[0.01]$} & {$[0.00]$} & {$[0.46]$} & {$[0.03]$} \\
\hline \multirow[t]{2}{*}{ Constant } & $96.305^{* * *}$ & & & $15.444^{* *}$ & & \\
\hline & {$[0.00]$} & & & {$[0.01]$} & & \\
\hline $\mathrm{N}$ & 1718 & 1580 & 1515 & 1923 & 1715 & 1543 \\
\hline DV Mean & 5.14 & 5.15 & 5.14 & 0.09 & 0.10 & 0.11 \\
\hline Plant FE & $\checkmark$ & $\checkmark$ & $\checkmark$ & $\checkmark$ & $\checkmark$ & $\checkmark$ \\
\hline Year FE & $\checkmark$ & $\checkmark$ & $\checkmark$ & $\checkmark$ & $\checkmark$ & $\checkmark$ \\
\hline Reg. Trend & $\checkmark$ & $\checkmark$ & $\checkmark$ & $\checkmark$ & $\checkmark$ & $\checkmark$ \\
\hline $\mathrm{R}^{2}$ & 0.96 & 0.15 & 0.10 & 0.99 & 0.84 & 0.80 \\
\hline First stage F & & 6.87 & 3.50 & & 9.46 & 13.70 \\
\hline Unity Test $\mathrm{p}$ & 0.00 & 0.00 & 0.18 & 0.00 & 1.00 & 0.63 \\
\hline
\end{tabular}

Notes: The dependent variable (DV) is the log of labor or fuel input. The estimates for POST1991 and POST1999 are the difference-in-difference treatment effects for privatization and privatization and competition, respectively. The competition only effect is the difference. The estimator is OLS or IV with the first lag of output as instrument. For the IV regressions the table reports the first stage F-statistic. Unity test $\mathrm{p}$ is the p-value for the test that the output coefficient estimate equals one. All regressions include with plant fixed effects, year fixed effects, and regional trends. Standard errors clustered at the treatment level. In (3) and (6) the balanced sample only includes GB plants that are observed at least once before 1985 and once after 2001. p-values are in brackets: ${ }^{*} \mathrm{p}<0.05,{ }^{* *} \mathrm{p}<0.01,{ }^{* * *} \mathrm{p}<0.001$. 
The coefficients for the treatment effects, POST1991 and POST1999, capture the productivity shift due to privatization $\left(\delta^{P}\right)$ and the productivity shift due to privatization and competition $\left(\delta^{C}\right)$, respectively. As we estimate input demands, a positive (negative) intercept change implies a decrease (increase) in average input productivity. Using the approximation $[\exp (\delta)-1] \times 100$ we see that across the different estimates privatization increased labor productivity by between 26 and 31 per cent but decreased fuel productivity by between 6 and 10 per cent. Almost all effects are statistically significant. (Only the IV estimate for the unbalanced sample is statistically insignificant at a 10 per cent level). Compared to the results in Figure 1, the inclusion of regional trends and the different specification of the treatment effects, makes little difference for fuel, but the effects for labor productivity are lower. Consistent with the results of Fabrizio et al. (2007) the IV coefficient estimates for the treatment effects are generally lower than the OLS estimates. Across the two inputs there are no systematic differences between the results for the balanced and unbalanced samples. Despite US restructuring not affecting our control group, we test whether our results are robust to using a sub-sample of non-restructuring US states only. The results in Figure 7 in Appendix A show that the absolute sizes of the effects are smaller but that qualitatively the results are the same.

Why did fuel productivity decrease after privatization? Remember that we assume that fuel productivity can only be influenced a change in incentives. It seems that private plants with market power had weaker incentives than public plants. In particular, the exercise of market power might have increase the variability of output, reducing fuel productivity. Another possible explanation is a loss of economies of scope due to vertical separation. Arocena et al. (2012) find vertical economies of scope of about 12 percent for U.S. electric utilities, but the results are not directly comparable as economies of scope relate to total cost and not physical input quantity. The labor productivity effect is large but consistent with aggregate data (Newbery and Pollitt, 1997. Table 1). Nevertheless, it is likely to overestimate the true effect of privatization, because our measure of head count does not take into account changes in working hours or outsourcing after privatization. Assuming that a change in objectives does not affect fuel productivity, the combination of the positive labor productivity effect and the negative fuel productivity effect is evidence that privatization affected productivity through changes in objectives rather than incentives. Before privatization, power plants were over-staffed not because the public owner was unable to monitor and incentivize management, but because it benefited her politically. Thus, unlike Gupta (2005) for Indian privatizations, we find no evidence that privatization increased productivity through better incentives. Contrasting the results suggests that in GB public owners controlled and supervised management effectively. This interpretation is supported by 
anecdotal evidence. For instance, in GB the public owner encouraged fuel productivity through a culture that valued engineering excellence (Newbery, 1995). Also, the publication of statistical industry yearbooks, made it easy to benchmark plant performance. Probably, there was less transparency after privatization. Generally, studies that have single treatment cases, as the majority of studies in this area do, are not able to control for the institutional environment and therefore have external validity only in comparable environments.

What was the (additional) effect of the introduction of effective competition in 1999? Remember that in Table 3 the effect of competition is the difference between the two treatment indicators. For instance, in the first column the estimates suggest that competition decreased labor productivity by $13.5 \mathrm{log}$ points. As already suggested by the results in Figure 1 competition did not increase labor or fuel productivity relative to US plants. Actually, the labor productivity increase due to privatization was slightly reversed and fuel productivity decreased further. At face value these results suggest that competition decreased productivity, which in the light of the previous literature seems unlikely. Fabrizio et al. (2007) find that competition increases labor productivity by about 6 per cent, but does not have a statistically significant effect on fuel productivity. A possible explanation for the labor productivity reversal, consistent with anecdotal evidence, is that after privatization workforces were reduced to an unsustainably low level and plants had to hire again in the second half of the 1990s. That is, a late negative privatization effects might have overshadowed any positive competition effect. Also, it might be that there simply was no effective competition during the 1990s. Last, it might be that we date the onset of effective competition too late, thus overestimating the effect of privatization and underestimating the effect of competition. Figure 1 suggests that fuel productivity might have improved in relation to US plants between 1996 and 2000. Table 6 in the Appendix gives the results when we move the date for effective competition from 1999 to 1996 . For labor the coefficient estimates for both treatments are larger in absolute terms, but their relation is unchanged. For fuel all the privatization effects are statistically indistinguishable from zero at a 10 per cent level. However, for the IV estimates there is a sizable positive effect due to competition, which is statistically significant at a 10 but not at a 5 pert cent level. Taken together, our results provide robust evidence that privatization increased labor, but not fuel productivity. Also, our results show that competition if it ever became effective during the 1990s neither increased labor nor fuel productivity. 


\section{Summary and Conclusion}

This article contributes to the small literature that identifies the causal effects of privatization and competition on plant-level productivity as well as some of the mechanisms. The fact that some countries, including the United Kingdom, debate taking back into public ownership certain utility industries, makes the analysis of the mechanisms relevant. Using the case of the privatization of Great Britain's power plants, together with comparable US plants as control group, allows us to identify the privatization and competition effects using fixed effects, i.e. difference-in-difference, estimation. One mechanism that explains the productivity enhancing effect of privatization is that public and private owners' objectives are different. Whereas private owners maximize profit, public owners maximize political benefit, which often implies employing more inputs than strictly necessary. For instance, as labor votes, it is often politically beneficial for public owners to over-staff plants, thereby reducing labor productivity. An alternative explanation assumes that objectives are the same but that private owners are better able to set incentives, i.e. solve the principal-agent problem when ownership and management are separate. To separate the incentive from the objective mechanism we assume that labor and fuel productivities respond differently depending on the mechanism at play. Whereas public owners derive little political benefit from subsidizing fuel at the plant level, the benefit derived from surplus employment in terms of votes might be considerable. For the identification of the two mechanisms we assume that the objective mechanism, if relevant, only affects labor productivity, but that the incentive mechanism affects both labor and fuel productivities.

Related to the debate about which mechanism matters for privatization is a debate about whether privatization increases productivity by itself or only in combination with competition. Some of the theoretical arguments about how privatization improves incentives rely on privatization coinciding with the introduction of competition. These theories predict that privatization is necessary but that only competition is sufficient to increase productivity. The GB case allows us to separate the effects of privatization and effective competition by asking whether the introduction of effective competition after privatization had a separate effect on productivity. To identify the competition effect we assume that, even though a wholesale market for electricity was established at privatization, competition became effective only several years later. As it is not clear when exactly competition became effective we check two alternative dates.

We find that privatization increased labor productivity but decreased fuel productivity. Together, these changes are evidence that privatization increased productivity, because it changed owner's objectives, not because private owners are better able to incentivize management. There are different explanations for why fuel productivity decreased. It could be that competitive pres- 
sure for the privately owned oligopolists was lower than for the publicly owned monopolist or that there was an efficiency loss due to vertical separation of the industry at privatization. Our finding that the objective mechanism is the relevant one, contrasts with the opposite finding of Gupta (2005). We believe this can be explained by differences in public ownership. Public (and private) ownership can take many forms and might face different constraints in different institutional environments. Generally, as most studies in this literature have single treatment cases they cannot control for institutional differences at the treatment (mostly country) level which makes it difficult to compare results.

We find that the introduction of effective competition several years after privatization did not increase labor or fuel productivity (further). Given the extant literature it seems unlikely that competition had no effect. It could be that effective competition was introduced at privatization, preventing us from identifying the separate effects. But this is unlikely given that we find no increase in fuel productivity at privatization and given the extensive prior evidence that competition was weak right after privatization. Therefore, the most likely explanation is that despite the regulator's best effort there was no effective competition until the end of our sample period. In contrast to some of the previous privatization studies (Caves and Christensen, 1980, Bartel and Harrison, 2005) we find that privatization can increase productivity by itself, which is consistent with the finding that the ownership effect was more important than the incentive effect. Our results suggest that productivity losses from public ownership can be mitigated when public owners are sufficiently distanced from the political process so that owners cannot benefit certain constituencies at the expense of the wider public. 


\section{References}

Angrist, J. D. and Pischke, J.-S. (2008). Mostly harmless econometrics: An empiricist's companion. Princeton University Press.

Arocena, P., Saal, D. S., and Coelli, T. (2012). Vertical and Horizontal Scope Economies in the Regulated U.S. Electric Power Industry. The Journal of Industrial Economics, 60(3):434-467.

Arocena, P. and Waddams Price, C. (2002). Generating efficiency: economic and environmental regulation of public and private electricity generators in Spain. International Journal of Industrial Organization, 20:41-69. 1.

Atkinson, S. E. and Halvorsen, R. (1986). The relative efficiency of public and private firms in a regulated environment: The case of U.S. electric utilities. Journal of Public Economics, 29(3):281-294.

Bartel, A. P. and Harrison, A. E. (2005). Ownership versus environment: Disentangling the sources of public-sector inefficiency. Review of Economics and Statistics, 87(1):135-147.

Bertrand, M., Duflo, E., and Mullainathan, S. (2004). How Much Should We Trust DifferencesIn-Differences Estimates? The Quarterly Journal of Economics, 119(1):249-275.

Biesebroeck, J. v. (2003). Productivity Dynamics with Technology Choice: An Application to Automobile Assembly. The Review of Economic Studies, 70(1):167-198.

Boycko, M., Shleifer, A., and Vishny, R. W. (1996). A Theory of Privatisation. The Economic Journal, 106(435):309-319.

Bushnell, J. B. and Wolfram, C. D. (2005). Ownership change, incentives and plant efficiency: The divestiture of US electric generation plants. Center for the Study of Energy Markets Paper CSEMWP-140.

Caves, D. W. and Christensen, L. R. (1980). The Relative Efficiency of Public and Private Firms in a Competitive Environment: The Case of Canadian Railroads. Journal of Political Economy, 88(5):958-976.

D'souza, J. and Megginson, W. L. (1999). The Financial and Operating Performance of Privatized Firms during the 1990s. The Journal of Finance, 54(4):1397-1438.

Du, L., Mao, J., and Shi, J. (2009). Assessing the impact of regulatory reforms on China's electricity generation industry. Energy Policy, 37(2):712-720. 
Fabrizio, K. R., Rose, N., and Wolfram, C. D. (2007). Does Competition Reduce Cost? Assessing the Impact of Regulatory Restructuring on U.S. Electric Generation Efficiency. American Economic Review, 97:1250-1277. 4.

Frölich, M. (2008). Parametric and Nonparametric Regression in the Presence of Endogenous Control Variables. International Statistical Review, 76(2):214-227.

Galdón-Sánchez, J. E. and Schmitz, Jr., J. A. (2002). Competitive Pressure and Labor Productivity: World Iron-Ore Markets in the 1980's. American Economic Review, 92:1222-1235. 4.

Gao, H. and Van Biesebroeck, J. (2014). Effects of Deregulation and Vertical Unbundling on the Performance of China's Electricity Generation Sector. The Journal of Industrial Economics, $62(1): 41-76$.

Green, R. (2006). Market power mitigation in the UK power market. Utilities Policy, 14(2):7689.

Gupta, N. (2005). Partial privatization and firm performance. The Journal of Finance, 60(2):987-1015.

Hart, O. D. (1983). The market mechanism as an incentive scheme. The Bell Journal of Economics, pages 366-382.

Henney, A. (2010). The British Electric Industry, 1990-2010: The Rise and Demise of Competition. EEE Limited, London.

Hiebert, L. D. (2002). The Determinants of the Cost Efficiency of Electric Generating Plants: A Stochastic Frontier Approach. Southern Economic Journal, 68:935-946. 4.

Joskow, P. L. and Schmalensee, R. (1987). The Performance of Coal-Burning Electric Generating Units in the United States: 1960-1980. Journal of Applied Economics, 2:85-109. 2.

Knittel, C. R. (2002). Alternative Regulatory Methods and Firm Efficiency: Stochastic Frontier Evidence from the U.S. Electricity Industry. The Review of Economics and Statistics, 84:530540.

Leibenstein, H. (1966). Allocative Efficiency vs. 'X-Efficiency'. The American Economic Review, $56(3): 392-415$.

Newbery, D. M. (1995). Notes from visit to Drax. In personal communication, Cambridge. 
Newbery, D. M. (2004). Electricity liberalisation in Britain: the quest for a satisfactory wholesale market design. CMI Working Paper Series, 64.

Newbery, D. M. and Pollitt, M. G. (1997). The Restructuring and Privatisation of Britain's CEGB-Was It Worth It? The Journal of Industrial Economics, 45(3):269-303.

Nickell, S. J. (1996). Competition and Corporate Performance. Journal of Political Economy, 104:724-746. 4.

Pollitt, M. G. (1995). Ownership and Performance in Electric Utilities. Oxford University Press, Oxford-New York.

Pollitt, M. G. (1996). Ownership and efficiency in nuclear power production. Oxford Economic Papers, 48(2):342-360.

Pollitt, M. G. (1997). The restructuring and privatisation of the Electricity Supply Industry in Northern Ireland - will it be worth it? DAE Working Paper, University of Cambridge, No 9701.

Pollitt, M. G. (1999). The restructuring and privatization of the Electricity Supply Industry in Scotland. Cambridge University, Department of Applied Economics, mimeo.

Pollitt, M. G. (2012). The role of policy in energy transitions: Lessons from the energy liberalisation era. Energy Policy, 50:128-137.

Schmidt, K. M. (1996). The Costs and Benefits of Privatization: An Incomplete Contracts Approach. Journal of Law, Economics, and Organization, 12(1):1-24.

Schmidt, K. M. (1997). Managerial Incentives and Product Market Competition. The Review of Economic Studies, 64(2):191-213.

Shleifer, A. (1998). State versus Private Ownership. Journal of Economic Perspectives, 12(4):133-150.

Shleifer, A. and Vishny, R. W. (1994). Politicians and firms. The Quarterly Journal of Economics, pages $995-1025$.

Sweeting, A. (2007). Market Power In The England And Wales Wholesale Electricity Market 1995-2000. The Economic Journal, 117(520):654-685.

Syverson, C. (2004). Market Structure and Productivity: A Concrete Example. Journal of Political Economy, 112(6):1181-1222. 
Vickers, J., Yarrow, G., Rochet, J.-C., and Venables, A. (1991). The British Electricity Experiment. Economic Policy, 6(12):187-232.

Waddams Price, C. and Weyman-Jones, T. (1996). Malmquist indices of productivity change in the UK Gas industry before and after privatization. Applied Economics, 28:29-39.

Willig, R. D. (1987). Corporate Governance and Market Structure. In Razin, A. and Sadka, E., editors, Economic Policy in Theory and Practice, pages 481-503. Palgrave Macmillan UK. 


\section{A. Robustness}

\section{A.1. Choice of Instruments}

As discussed above, identification would be threatened if one of the control variables was not fully exogenous. Above, to deal with the potential endogeneity of output in the input demand equations we instrument output with its first lag. Here we contrast this instrument with an alternative instrument: aggregate sales, including region-indicator interactions as we do not have regional sales for GB. Tables 4 and 5 contrast the input demand coefficient estimates for the OLS and IV estimators, for fuel and labor, respectively. To better compare the instruments we omit the treatment effects here. Whereas, in each table the first three columns are for all observations, the last three columns are for the sub-sample of non-missing values only. (Remember that for some variables we replace missing values with proxies.) A comparison of columns (2) and (3) as well as (5) and (6) in Table 4 suggests that lagged output is the better instrument. First, unlike for aggregate sales, the first stage is always significant. Second, unlike for aggregate sales, for lagged output the OLS bias always has the expected and usual negative sign. For electricity generation, it is reasonable to believe that omitted variables, e.g. unobserved outage for maintenance, are negatively correlated with output and positively correlated with input. These results are the same for the labor demand equations in Table 5 . Last, for fuel but not for labor, with lagged output as instrument we cannot reject the Null that the output coefficient value equals one, as is consistent with the production function's Cobb-Douglas form. 
Table 4: Test of Instruments: Fuel Demand Estimates without Treatment Indicators

\begin{tabular}{|c|c|c|c|c|c|c|}
\hline \multirow[b]{4}{*}{ Instrument } & $(1)$ & $(2)$ & (3) & (4) & $(5)$ & (6) \\
\hline & \multicolumn{3}{|c|}{ All observations } & \multicolumn{3}{|c|}{ Non-missing only } \\
\hline & \multirow[t]{2}{*}{ OLS } & \multicolumn{2}{|c|}{ IV } & \multirow[t]{2}{*}{ OLS } & \multicolumn{2}{|c|}{ IV } \\
\hline & & Aggregate sales & Lagged output & & Aggregate sales & Lagged output \\
\hline \multirow[t]{2}{*}{$\ln (\mathrm{NET} \mathrm{GWH})$} & $0.923^{* * *}$ & $0.820^{* * *}$ & $1.006^{* * *}$ & $0.916^{* * *}$ & $0.942^{* * *}$ & $1.002^{* * *}$ \\
\hline & {$[0.00]$} & {$[0.00]$} & {$[0.00]$} & {$[0.00]$} & {$[0.00]$} & {$[0.00]$} \\
\hline \multirow[t]{2}{*}{$\ln (\mathrm{CAP})$} & -0.056 & 0.063 & -0.138 & 0.050 & 0.019 & -0.039 \\
\hline & {$[0.52]$} & {$[0.60]$} & {$[0.11]$} & {$[0.31]$} & {$[0.94]$} & {$[0.83]$} \\
\hline \multirow[t]{2}{*}{ Load factor } & -0.042 & 0.227 & -0.233 & 0.002 & -0.062 & -0.155 \\
\hline & {$[0.49]$} & {$[0.39]$} & {$[0.19]$} & {$[0.98]$} & {$[0.90]$} & {$[0.67]$} \\
\hline \multirow[t]{2}{*}{ Age (years) } & $-0.016^{*}$ & $-0.016^{* *}$ & $-0.027^{* * *}$ & $-0.017^{*}$ & $-0.017^{* *}$ & $-0.027^{* *}$ \\
\hline & {$[0.02]$} & {$[0.01]$} & {$[0.00]$} & {$[0.02]$} & {$[0.01]$} & {$[0.00]$} \\
\hline \multirow[t]{2}{*}{ FGD } & $0.042^{*}$ & 0.055 & 0.040 & 0.029 & 0.027 & 0.025 \\
\hline & {$[0.01]$} & {$[0.17]$} & {$[0.35]$} & {$[0.12]$} & {$[0.63]$} & {$[0.69]$} \\
\hline \multirow[t]{2}{*}{ Constant } & 1.769 & & & $18.859^{* * *}$ & & \\
\hline & {$[0.45]$} & & & {$[0.00]$} & & \\
\hline $\mathrm{N}$ & 1923 & 1923 & 1715 & 1591 & 1591 & 1435 \\
\hline DV Mean & 0.06 & 0.06 & 0.07 & 0.09 & 0.09 & 0.10 \\
\hline Plant FE & $\checkmark$ & $\checkmark$ & $\checkmark$ & $\checkmark$ & $\checkmark$ & $\checkmark$ \\
\hline Year FE & $\checkmark$ & $\checkmark$ & $\checkmark$ & $\checkmark$ & $\checkmark$ & $\checkmark$ \\
\hline Reg. Trend & $\checkmark$ & $\checkmark$ & $\checkmark$ & $\checkmark$ & $\checkmark$ & $\checkmark$ \\
\hline $\mathrm{R}^{2}$ & 0.99 & 0.88 & 0.87 & 0.99 & 0.85 & 0.82 \\
\hline First stage F & & 1.78 & 157.21 & & 0.77 & 65.90 \\
\hline Overid. test F & & 80.01 & & & 51.62 & \\
\hline Unity Test p & 0.00 & 0.07 & 0.93 & 0.06 & 0.77 & 0.99 \\
\hline
\end{tabular}

Notes: The dependent variable (DV) is the log of fuel input. The estimator is OLS or IV. The instrument is aggregate sales (including region indicator interactions) or the first lag of output. For the IV regressions the table reports the first stage and overidentification test F-statistics. Unity test $\mathrm{p}$ is the p-value for the test that the output coefficient estimate equals one. All regressions include with plant fixed effects, year fixed effects, and regional trends. Standard errors clustered at the treatment level. $\mathrm{p}$-values are in brackets: $* \mathrm{p}<0.05, * * \mathrm{p}<0.01, * * *$ $\mathrm{p}<0.001$. 
Table 5: Test of Instruments: Labor Demand Estimates without Treatment Indicators

\begin{tabular}{|c|c|c|c|c|c|c|}
\hline \multirow[b]{3}{*}{ Instrument } & \multicolumn{2}{|r|}{ All observations } & (3) & \multicolumn{2}{|r|}{ Non-missing only } & (6) \\
\hline & \multirow[t]{2}{*}{ OLS } & \multicolumn{2}{|c|}{ IV } & \multirow[t]{2}{*}{ OLS } & \multicolumn{2}{|c|}{ IV } \\
\hline & & Aggregate sales & Lagged output & & Aggregate sales & Lagged output \\
\hline \multirow[t]{2}{*}{$\ln (\mathrm{NET} \mathrm{GWH})$} & 0.068 & -0.215 & $0.255^{*}$ & 0.025 & -0.171 & 0.177 \\
\hline & {$[0.28]$} & {$[0.14]$} & {$[0.03]$} & [0.65] & {$[0.28]$} & {$[0.18]$} \\
\hline \multirow[t]{2}{*}{$\ln (\mathrm{CAP})$} & $0.535^{* *}$ & $0.839^{* * *}$ & $0.346^{* *}$ & $0.549^{* *}$ & $0.762^{* * *}$ & $0.391^{* *}$ \\
\hline & {$[0.01]$} & {$[0.00]$} & {$[0.01]$} & {$[0.01]$} & {$[0.00]$} & {$[0.01]$} \\
\hline \multirow[t]{2}{*}{ Load factor } & 0.159 & $0.867^{*}$ & -0.289 & $0.219^{*}$ & 0.705 & -0.156 \\
\hline & {$[0.10]$} & {$[0.02]$} & {$[0.32]$} & {$[0.04]$} & {$[0.07]$} & {$[0.63]$} \\
\hline \multirow[t]{2}{*}{$\ln$ (WAGE) } & -0.048 & $-0.057^{*}$ & -0.018 & -0.076 & $-0.080^{* * *}$ & $-0.052^{*}$ \\
\hline & {$[0.40]$} & {$[0.02]$} & {$[0.45]$} & {$[0.12]$} & {$[0.00]$} & {$[0.03]$} \\
\hline \multirow[t]{2}{*}{ Age (years) } & 0.021 & $0.021^{*}$ & $0.031^{* *}$ & 0.021 & $0.020^{* *}$ & $0.029^{* *}$ \\
\hline & {$[0.12]$} & {$[0.01]$} & {$[0.00]$} & [0.13] & {$[0.01]$} & {$[0.00]$} \\
\hline \multirow[t]{2}{*}{ FGD } & 0.018 & 0.053 & -0.001 & 0.077 & 0.100 & 0.076 \\
\hline & {$[0.61]$} & [0.34] & {$[0.98]$} & {$[0.08]$} & {$[0.08]$} & {$[0.20]$} \\
\hline \multirow[t]{2}{*}{ Constant } & $137.409^{* * *}$ & & & $138.080^{* * *}$ & & \\
\hline & {$[0.00]$} & & & {$[0.00]$} & & \\
\hline $\mathrm{N}$ & 1718 & 1717 & 1580 & 1660 & 1659 & 1508 \\
\hline DV Mean & 5.14 & 5.14 & 5.15 & 5.12 & 5.12 & 5.12 \\
\hline Plant FE & $\checkmark$ & $\checkmark$ & $\checkmark$ & $\checkmark$ & $\checkmark$ & $\checkmark$ \\
\hline Year FE & $\checkmark$ & $\checkmark$ & $\checkmark$ & $\checkmark$ & $\checkmark$ & $\checkmark$ \\
\hline Reg. Trend & $\checkmark$ & $\checkmark$ & $\checkmark$ & $\checkmark$ & $\checkmark$ & $\checkmark$ \\
\hline $\mathrm{R}^{2}$ & 0.96 & 0.64 & 0.67 & 0.96 & 0.65 & 0.66 \\
\hline First stage $\mathrm{F}$ & & 1.87 & 92.61 & & 1.66 & 79.22 \\
\hline Overid. test $\mathrm{F}$ & & 100.64 & & & 104.26 & \\
\hline Unity Test p & 0.00 & 0.00 & 0.00 & 0.00 & 0.00 & 0.00 \\
\hline
\end{tabular}

Notes: The dependent variable (DV) is the log of labor input. The estimator is OLS or IV. The instrument is aggregate sales (including region indicator interactions) or the first lag of output. For the IV regressions the table reports the first stage and overidentification test F-statistics. Unity test $\mathrm{p}$ is the p-value for the test that the output coefficient estimate equals one. All regressions include with plant fixed effects, year fixed effects, and regional trends. Standard errors clustered at the treatment level. $\mathrm{p}$-values are in brackets: $* \mathrm{p}<0.05, * * \mathrm{p}<0.01, * * *$ $\mathrm{p}<0.001$. 


\section{A.2. Treatment effect for different sub-samples}

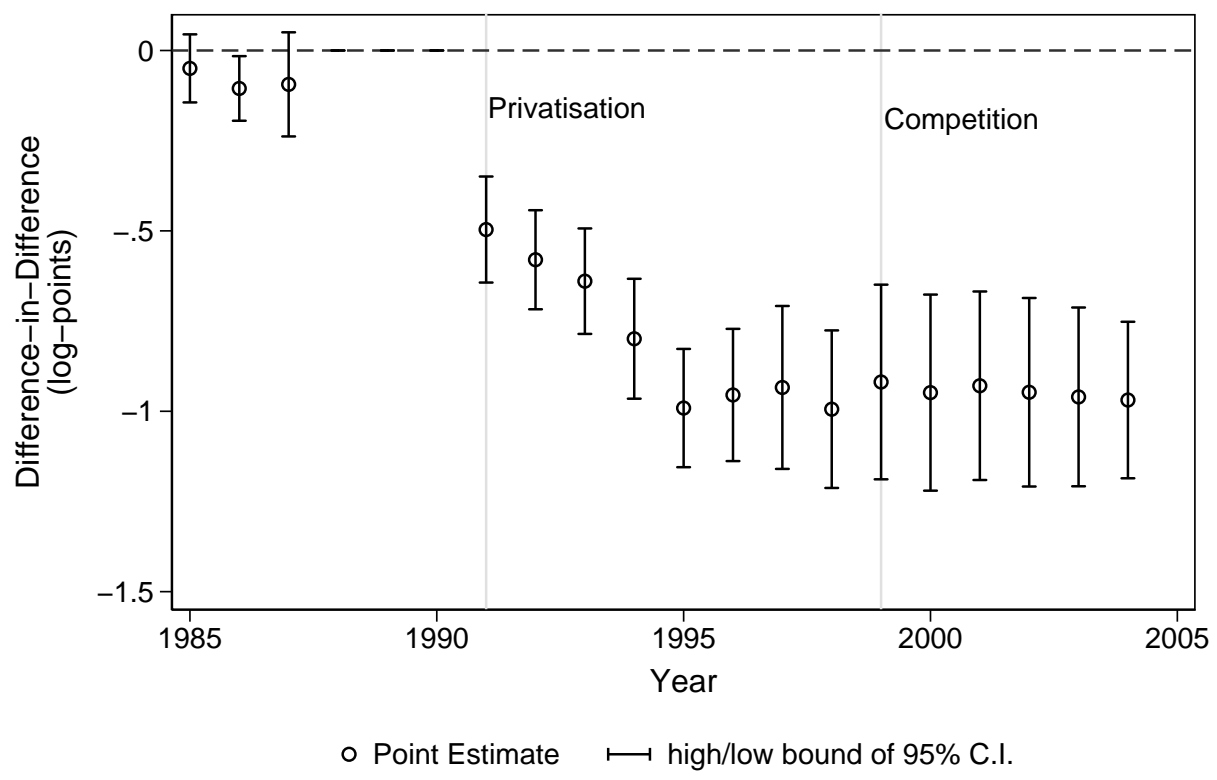

(a) Labor

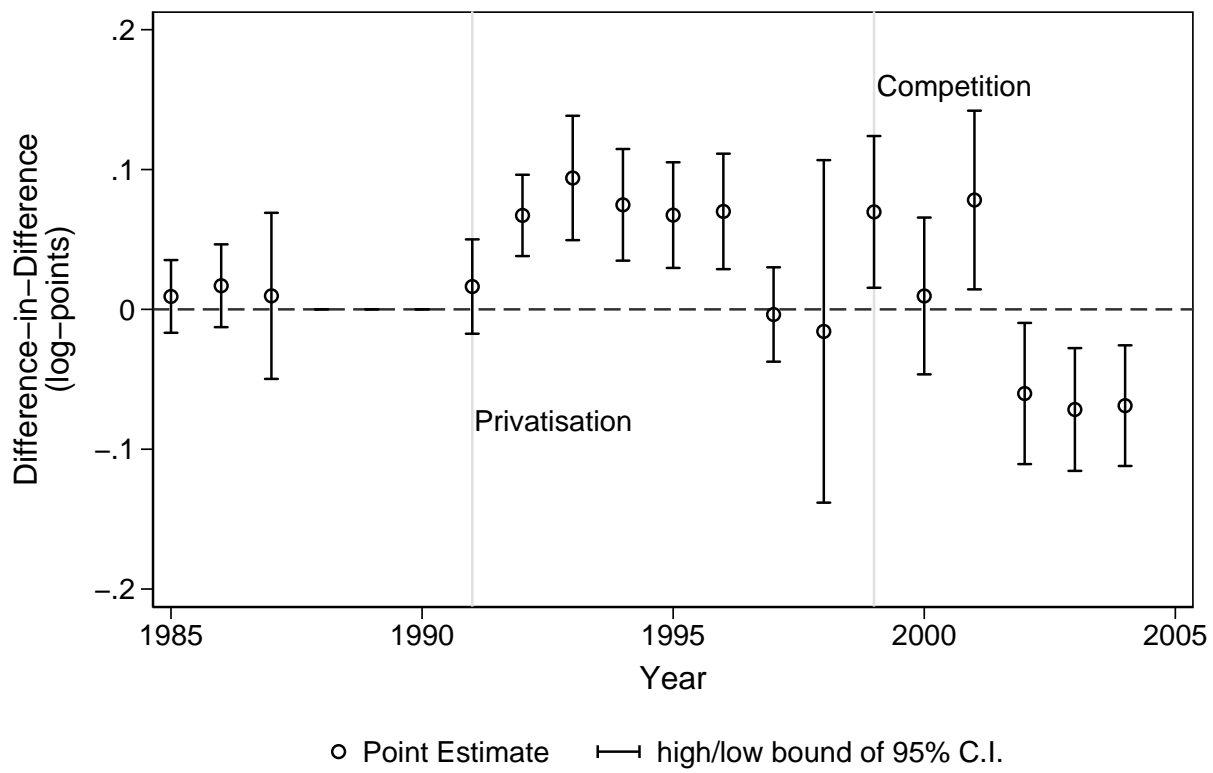

(b) Fuel

Figure 2: Year-specific treatment effects (Other input non-missing)

Notes: The graphs plot the coefficient estimates, in log-points, for the year-specific input productivity differences (treatment effects) between GB and the US, the control group. The differences are estimated as part of input demand equations at the plant level. The estimator is OLS with panel fixed effects and standard errors clustered at the treatment level. The upper panel is for labor productivity and the lower panel is for fuel productivity. The vertical bars give the $95 \%$ confidence intervals. A positive (negative) estimate represents a decrease (increase) in productivity. The two vertical lines indicate the dates for privatization and the introduction of competition in Great Britain. The data is for the sub-samples where the other input is non-missing, e.g. the gaps for the labor productivity are due to missing values for fuel input. 


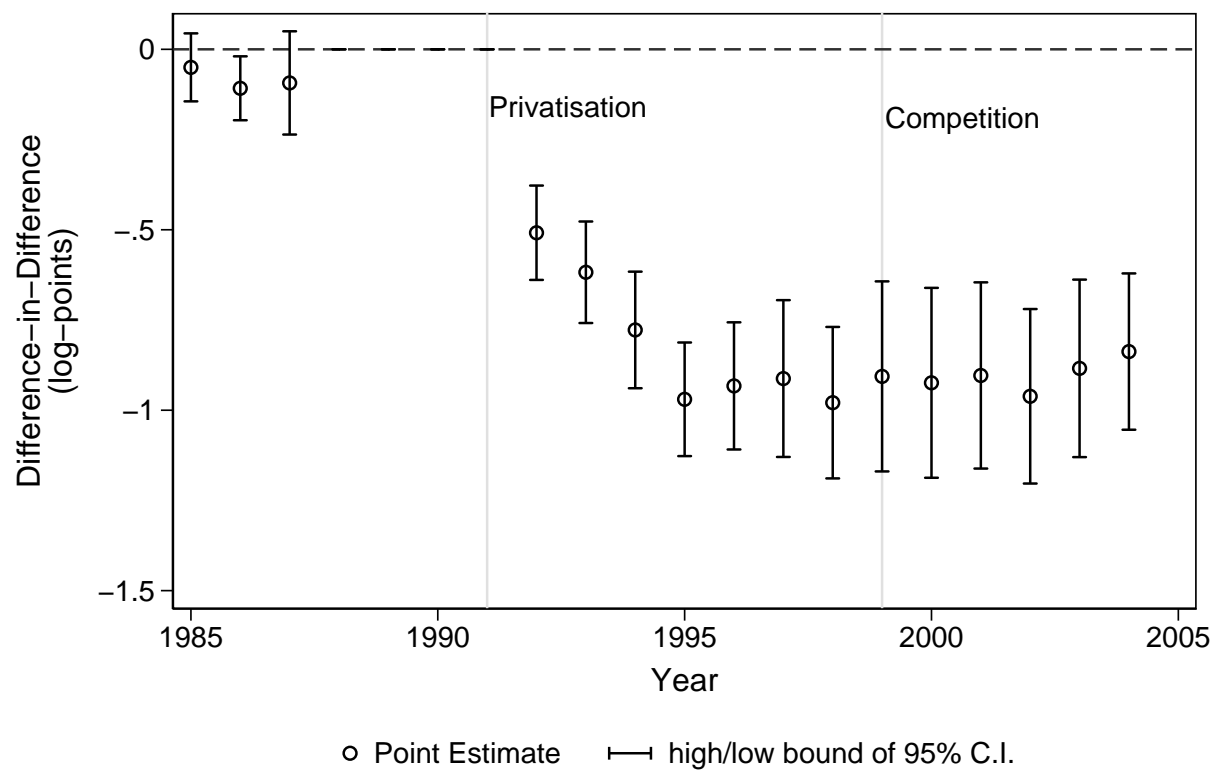

(a) Labor

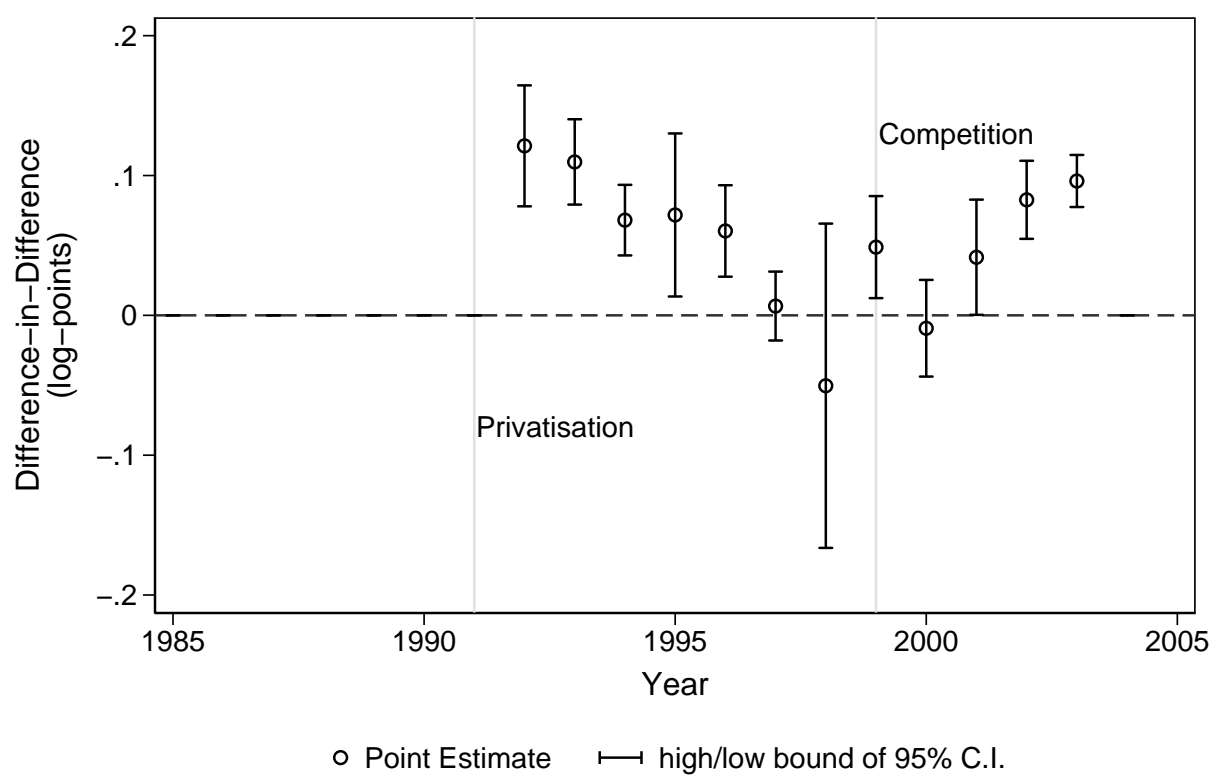

(b) Fuel

Figure 3: Year-specific treatment effects (Non-missing observations only)

Notes: The graphs plot the coefficient estimates, in log-points, for the year-specific input productivity differences (treatment effects) between GB and the US, the control group. The differences are estimated as part of input demand equations at the plant level. The estimator is OLS with panel fixed effects and standard errors clustered at the treatment level. The upper panel is for labor productivity and the lower panel is for fuel productivity. The vertical bars give the $95 \%$ confidence intervals. A positive (negative) estimate represents a decrease (increase) in productivity. The two vertical lines indicate the dates for privatization and the introduction of competition in Great Britain. The data is for the sub-samples of non-missing values. 
A.3. Alternative treatment dates 
Table 6: Treatment effects for privatization and competition

\begin{tabular}{|c|c|c|c|c|c|c|}
\hline \multirow[b]{3}{*}{ Balanced sample } & \multicolumn{3}{|c|}{$\ln$ (Labor) } & \multicolumn{3}{|c|}{$\ln ($ Fuel $)$} \\
\hline & \multirow{2}{*}{$\begin{array}{c}\text { OLS } \\
\mathrm{N}\end{array}$} & \multicolumn{2}{|c|}{ IV } & \multirow{2}{*}{$\begin{array}{c}\text { OLS } \\
\mathrm{N}\end{array}$} & \multicolumn{2}{|c|}{ IV } \\
\hline & & $\mathrm{N}$ & $\mathrm{Y}$ & & $\mathrm{N}$ & $\mathrm{Y}$ \\
\hline \multirow[t]{2}{*}{$\ln (\mathrm{NET}$ GWH) } & 0.054 & 0.285 & 0.362 & $0.929^{* * *}$ & $1.003^{* * *}$ & $1.076^{* * *}$ \\
\hline & {$[0.35]$} & {$[0.07]$} & {$[0.40]$} & {$[0.00]$} & {$[0.00]$} & {$[0.00]$} \\
\hline \multirow[t]{2}{*}{$\ln (\mathrm{CAP})$} & $0.532^{* *}$ & 0.301 & 0.225 & -0.060 & -0.134 & -0.127 \\
\hline & {$[0.01]$} & {$[0.16]$} & {$[0.62]$} & {$[0.48]$} & {$[0.15]$} & {$[0.54]$} \\
\hline \multirow[t]{2}{*}{ LF } & 0.178 & -0.377 & -0.537 & -0.068 & -0.241 & -0.352 \\
\hline & {$[0.06]$} & {$[0.26]$} & {$[0.56]$} & {$[0.32]$} & {$[0.19]$} & {$[0.45]$} \\
\hline \multirow[t]{2}{*}{ AGE } & 0.021 & 0.029 & 0.029 & $-0.016^{*}$ & $-0.027^{* * *}$ & $-0.028^{* * *}$ \\
\hline & {$[0.13]$} & {$[0.10]$} & {$[0.08]$} & {$[0.02]$} & {$[0.00]$} & {$[0.00]$} \\
\hline \multirow[t]{2}{*}{$\ln ($ WAGE) } & -0.075 & -0.045 & -0.039 & & & \\
\hline & {$[0.13]$} & {$[0.27]$} & {$[0.40]$} & & & \\
\hline \multirow[t]{2}{*}{ FGD } & 0.046 & 0.013 & 0.009 & $0.054^{* *}$ & $0.054^{* * *}$ & $0.046^{* *}$ \\
\hline & {$[0.23]$} & {$[0.75]$} & {$[0.83]$} & {$[0.00]$} & {$[0.00]$} & {$[0.00]$} \\
\hline \multirow[t]{2}{*}{ POST1991 } & $-0.401^{* * *}$ & $-0.357^{* * *}$ & $-0.348^{* * *}$ & 0.017 & -0.022 & -0.023 \\
\hline & {$[0.00]$} & {$[0.00]$} & {$[0.00]$} & {$[0.59]$} & {$[0.61]$} & {$[0.54]$} \\
\hline \multirow[t]{2}{*}{ POST1996 } & $-0.380^{* * *}$ & $-0.342^{* * *}$ & $-0.341^{* * *}$ & -0.060 & -0.145 & -0.127 \\
\hline & {$[0.00]$} & {$[0.00]$} & {$[0.00]$} & {$[0.33]$} & {$[0.07]$} & {$[0.07]$} \\
\hline \multirow[t]{2}{*}{ Constant } & $88.058^{* * *}$ & & & -2.785 & & \\
\hline & {$[0.00]$} & & & {$[0.67]$} & & \\
\hline $\mathrm{N}$ & 1718 & 1580 & 1515 & 1923 & 1715 & 1543 \\
\hline DV Mean & 5.14 & 5.15 & 5.14 & 0.09 & 0.10 & 0.11 \\
\hline Plant FE & $\checkmark$ & $\checkmark$ & $\checkmark$ & $\checkmark$ & $\checkmark$ & $\checkmark$ \\
\hline Year FE & $\checkmark$ & $\checkmark$ & $\checkmark$ & $\checkmark$ & $\checkmark$ & $\checkmark$ \\
\hline Reg. Trend & $\checkmark$ & $\checkmark$ & $\checkmark$ & $\checkmark$ & $\checkmark$ & $\checkmark$ \\
\hline $\mathrm{R}^{2}$ & 0.96 & 0.15 & 0.11 & 0.99 & 0.84 & 0.80 \\
\hline First stage F & & 7.06 & 3.40 & & 9.71 & 13.34 \\
\hline Unity Test p & 0.00 & 0.00 & 0.14 & 0.01 & 0.95 & 0.68 \\
\hline
\end{tabular}

Notes: The dependent variable (DV) is the log of labor or fuel input. The estimates for POST1991 and POST1996 are the difference-in-difference treatment effects for privatization and privatization and competition, respectively. The competition only effect is the difference. The estimator is OLS or IV with the first lag of output as instrument. For the IV regressions the table reports the first stage F-statistic. Unity test $\mathrm{p}$ is the p-value for the test that the output coefficient estimate equals one. All regressions include with plant fixed effects, year fixed effects, and regional trends. Standard errors clustered at the treatment level. In (3) and (6) the balanced sample only includes GB plants that are observed at least once before 1985 and once after 2001. p-values are in brackets: ${ }^{*} \mathrm{p}<0.05,{ }^{* *} \mathrm{p}<0.01,{ }^{* * *} \mathrm{p}<0.001$. 
A.4. Alternative control group 
Table 7: Treatment effects for privatization and competition

\begin{tabular}{|c|c|c|c|c|c|c|}
\hline \multirow[b]{3}{*}{ Balanced sample } & \multicolumn{3}{|c|}{$\ln ($ Labor $)$} & \multicolumn{3}{|c|}{$\ln ($ Fuel $)$} \\
\hline & \multirow{2}{*}{$\begin{array}{c}\text { OLS } \\
\mathrm{N}\end{array}$} & \multicolumn{2}{|c|}{ IV } & \multirow{2}{*}{$\frac{\text { OLS }}{\mathrm{N}}$} & \multicolumn{2}{|c|}{ IV } \\
\hline & & $\mathrm{N}$ & $\mathrm{Y}$ & & $\mathrm{N}$ & $\mathrm{Y}$ \\
\hline \multirow[t]{2}{*}{$\ln (\mathrm{NET}$ GWH$)$} & 0.039 & 0.312 & 0.432 & $0.923^{* * *}$ & $0.987^{* * *}$ & $1.047^{* * *}$ \\
\hline & {$[0.53]$} & {$[0.05]$} & {$[0.44]$} & {$[0.00]$} & {$[0.00]$} & {$[0.00]$} \\
\hline \multirow[t]{2}{*}{$\ln (\mathrm{CAP})$} & $0.489^{*}$ & 0.214 & 0.097 & -0.077 & -0.125 & -0.081 \\
\hline & {$[0.03]$} & {$[0.37]$} & {$[0.87]$} & {$[0.40]$} & {$[0.22]$} & {$[0.74]$} \\
\hline \multirow[t]{2}{*}{$\mathrm{LF}$} & $0.251^{*}$ & -0.461 & -0.724 & -0.044 & -0.178 & -0.256 \\
\hline & {$[0.02]$} & {$[0.21]$} & {$[0.56]$} & {$[0.51]$} & {$[0.33]$} & {$[0.65]$} \\
\hline \multirow[t]{2}{*}{ AGE } & 0.021 & 0.032 & 0.033 & $-0.016^{*}$ & $-0.027^{* * *}$ & $-0.028^{* * *}$ \\
\hline & {$[0.16]$} & {$[0.11]$} & {$[0.08]$} & {$[0.03]$} & {$[0.00]$} & {$[0.00]$} \\
\hline \multirow[t]{2}{*}{$\ln ($ WAGE) } & 0.067 & $0.117^{*}$ & $0.147^{*}$ & & & \\
\hline & {$[0.37]$} & {$[0.03]$} & {$[0.02]$} & & & \\
\hline \multirow[t]{2}{*}{ FGD } & $0.047^{* *}$ & 0.011 & 0.008 & $0.026^{* *}$ & $0.031^{* *}$ & $0.040^{*}$ \\
\hline & {$[0.00]$} & {$[0.64]$} & {$[0.80]$} & {$[0.00]$} & {$[0.00]$} & {$[0.04]$} \\
\hline \multirow[t]{2}{*}{ POST1991 } & $-0.354^{* * *}$ & $-0.295^{* * *}$ & $-0.276^{* * *}$ & $0.082^{*}$ & 0.043 & 0.074 \\
\hline & {$[0.00]$} & {$[0.00]$} & {$[0.00]$} & {$[0.01]$} & {$[0.42]$} & {$[0.07]$} \\
\hline \multirow[t]{2}{*}{ POST1999 } & $-0.221^{*}$ & $-0.168^{*}$ & -0.150 & 0.123 & 0.045 & 0.117 \\
\hline & {$[0.01]$} & {$[0.04]$} & {$[0.10]$} & {$[0.05]$} & {$[0.67]$} & {$[0.15]$} \\
\hline \multirow[t]{2}{*}{ Constant } & $103.897^{* * *}$ & & & 14.820 & & \\
\hline & [0.00] & & & {$[0.06]$} & & \\
\hline $\mathrm{N}$ & 1228 & 1126 & 1061 & 1442 & 1271 & 1099 \\
\hline DV Mean & 5.21 & 5.22 & 5.22 & 0.15 & 0.17 & 0.18 \\
\hline Plant FE & $\checkmark$ & $\checkmark$ & $\checkmark$ & $\checkmark$ & $\checkmark$ & $\checkmark$ \\
\hline Year FE & $\checkmark$ & $\checkmark$ & $\checkmark$ & $\checkmark$ & $\checkmark$ & $\checkmark$ \\
\hline Reg. Trend & $\checkmark$ & $\checkmark$ & $\checkmark$ & $\checkmark$ & $\checkmark$ & $\checkmark$ \\
\hline $\mathrm{R}^{2}$ & 0.97 & 0.15 & 0.08 & 0.99 & 0.85 & 0.81 \\
\hline First stage F & & 5.61 & 1.82 & & 8.93 & 9.10 \\
\hline Unity Test $\mathrm{p}$ & 0.00 & 0.00 & 0.31 & 0.01 & 0.81 & 0.83 \\
\hline
\end{tabular}

Notes: The dependent variable (DV) is the log of labor or fuel input. The estimates for POST1991 and POST1996 are the difference-in-difference treatment effects for privatization and privatization and competition, respectively. The competition only effect is the difference. The US counterfactual includes non-restructuring states only. The estimator is OLS or IV with the first lag of output as instrument. For the IV regressions the table reports the first stage F-statistic. Unity test $\mathrm{p}$ is the p-value for the test that the output coefficient estimate equals one. All regressions include with plant fixed effects, year fixed effects, and regional trends. Standard errors clustered at the treatment level. In (3) and (6) the balanced sample only includes GB plants that are observed at least once before 1985 and once after 2001. p-values are in brackets: ${ }^{*} \mathrm{p}<0.05,{ }^{* *} \mathrm{p}<0.01,{ }^{* * *} \mathrm{p}<0.001$. 


\section{B. Sources and derivation of missing values for GB data.}

For Great Britain, our data sources are the Central Electricity Generating Board's (CEGB) statistical yearbooks, company reports, government sources like the Digest of UK Energy Statistics (DUKES), and the companies that own plants. DUKES, which lists all UK power plants provides our sampling frame for GB. Essentially, the sampling frame is the population of all GB coal-fired plants. An important data source for the years before privatization is the CEGB yearbooks. However, these only provide plant capacity and fuel efficiency, probably because these values were of primary interest to engineers; others like labor productivity were not. Generally, publicly available data might reflect a firm's or government's desire to measure specific performance aspects, but not necessarily broad performance as we do. After we pulled together all publicly available data, we contacted the majority of plant owners with requests for data to fill the gaps. We guaranteed to treat all company data confidentially. Nevertheless, responses varied across companies and the responses we received were not always complete in the sense that we were not able to fill all the data gaps, i.e. have complete time series for all variables and all plants. We had no indication that non-responses or incomplete responses were in any way systematic. An often cited reason for no or incomplete responses was that the data was no longer available at plant or company archives. Our company contacts were mostly company managers that often had to contact plants to get the data. There might have been differences in how much effort firms put into compiling the data for us, but again there were no indications that these differences were systematic.

Finally, for several variables we replace remaining missing values with proxies. Where the proxy itself is missing, the gap remains. Note that any missing values for the US are left as missing. The literature provides different strategies to deal with missing values: ignore them, intrapolation/extrapolation, proxies, or dummy indicators in the regression equation. In the extant literature the most widely used approaches are to simply ignore observations with missing values (e.g. Fabrizio et al., 2007) or to use proxies (e.g. Gao and Van Biesebroeck, 2014 21. We use proxies due to the availability of data and the engineering/physical relationships available for electricity generation. Next we describe the use of these proxies one at a time.

For several observations we do not have data for fuel input, but we observe $\mathrm{CO} 2$ emissions. When contacting companies we also requested CO2 emissions and several companies published environmental reports throughout the 1990s (publication might be biased towards firms that are more fuel efficient). Where possible we derive missing fuel input from $\mathrm{CO} 2$ emissions as

\footnotetext{
${ }^{21}$ Gao and Van Biesebroeck (2014) do not observe prices and use proxies like plant age, size and location instead.
} 
follows.

\section{Fuel input from CO2:}

We derive the amount of coal input from the amount of $\mathrm{CO} 2$ emission using 0.407 as the conversion factor. The conversion factor is constant across plants and time.

Before privatization all fuel input values are missing and we derive them from plant-level fuel efficiency (from the CEGB yearbook).

\section{Fuel input from fuel efficiency:}

We derive the amount of coal input from the observed output and plant fuel efficiency.

Finally, we also derive missing electricity output from CO2 emissions, but only for the labor demand equation, to avoid having a dependent and independent variable derived from the same proxy.

\section{Output from CO2 (for labor demand equation only):}

We derive output from $\mathrm{CO} 2$ emissions as follows:

$$
G W h(\text { Supply })=k t(C O 2) * E F * E f f,
$$

where EF is the emissions factor, Eff is thermal efficiency. Where a plant-specific efficiency measure is not observed we use a generic measure equal to 0.36 (and 0.38 for the largest plant). We suggest that the use of the generic measure is acceptable as labor input generally varies less with output. Any values that remain missing after these derivations are left as missing.

For fuel input and output, Table 8 compares the means of the sub-sample of the originally observed data with the means of the complete sample, i.e. including the derived values as described above. The table shows that for these two variables more than half of the total number of observations is derived. Also, the means for the complete sample are much smaller, indicating that our original data is biased towards large plants. But remember that at least our qualitative results do not seem to be affected by this bias. 
Table 8: Summary Statistics for Variables with Derived Values

\begin{tabular}{|c|c|c|c|}
\hline & Observed & Derived & \multirow{3}{*}{$\frac{\text { t-stat. for diff. }}{\text { S.E. }}$} \\
\hline & \multicolumn{2}{|c|}{ Means } & \\
\hline & S.D. & S.D. & \\
\hline \multirow[t]{2}{*}{ Fuel (mtce) } & 2.98 & 1.72 & $-1.25^{* * *}$ \\
\hline & $(2.28)$ & (1.61) & $(0.18)$ \\
\hline $\mathrm{N}$ & 148 & 393 & \\
\hline \multirow[t]{2}{*}{ Output (net GWh) } & 7404.18 & 4722.87 & $-2681.31^{* * *}$ \\
\hline & $(5794.76)$ & $(4840.98)$ & $(468.61)$ \\
\hline $\mathrm{N}$ & 157 & 477 & \\
\hline
\end{tabular}

Notes: This table gives the means, standard deviations, and number of observations for samples without (observed) and with (derived) the derivation of some missing values. The sample is GB only. In the third column it also gives the t-statistic and standard error for the Null of equal means. ${ }^{*} \mathrm{p}<0.05,{ }^{* *} \mathrm{p}<0.01,{ }^{* * *} \mathrm{p}<0.001$ 